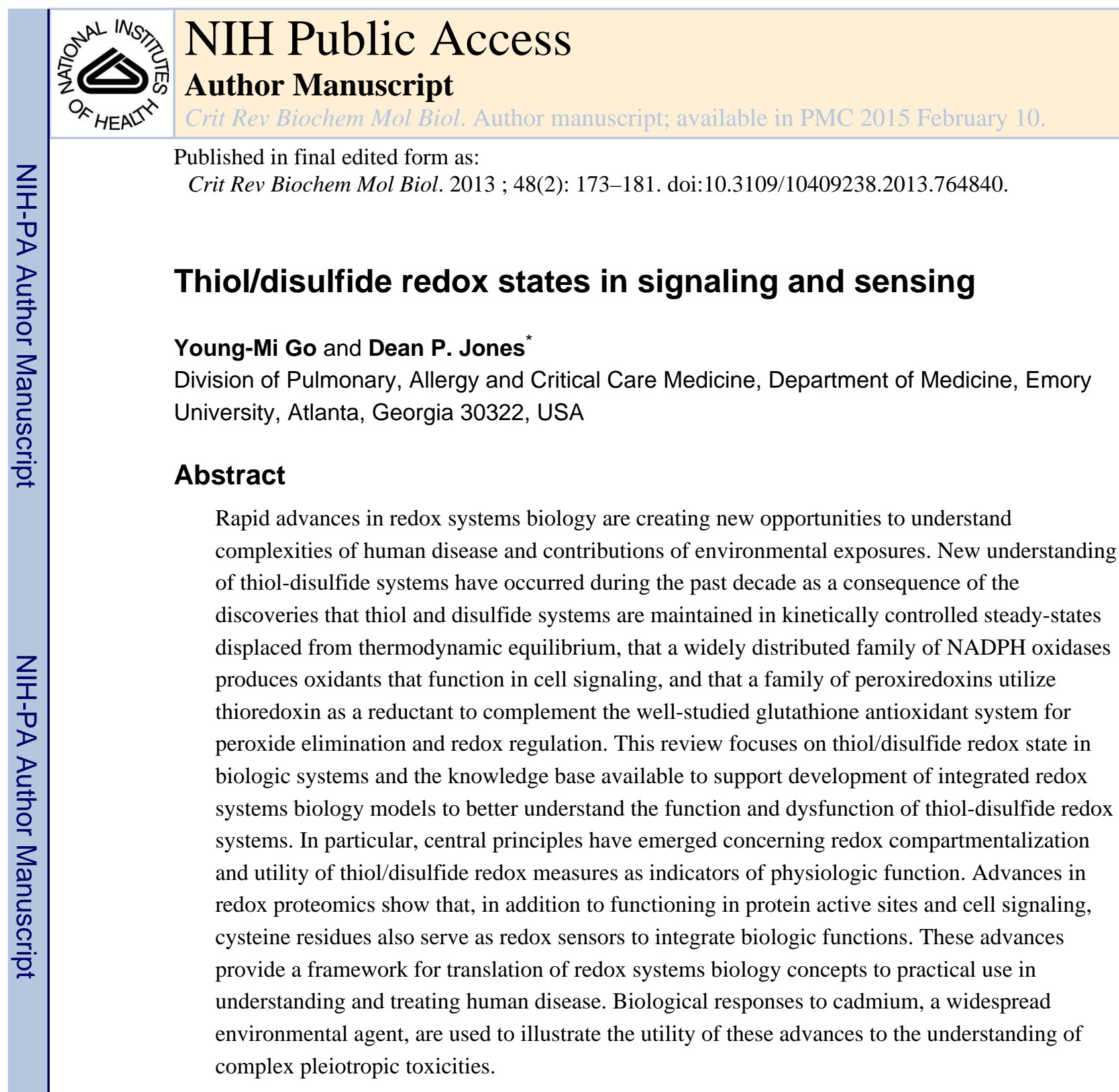

Keywords

Cysteine proteome; redox regulon; redox sensor; redox systems biology; thiol redox circuit

\title{
Introduction
}

An extensive scientific literature has amassed concerning thiols, disulfides and related aspects in biological systems. For instance, a PubMed search in August 2012 retrieved 94,477 papers on "thiol", 102,969 on "glutathione", 161,047 on "methionine or cysteine". This volume of scientific literature includes thousands of papers on thiols in enzyme active

*Corresponding author: Dean P. Jones, Ph.D., Emory University, 205 Whitehead Research Center, Atlanta, GA 30322. Tel: 404-727-5980. Fax: 404-712-2974. dpjones@emory.edu.

Declaration of Interest

This work was supported by the National Institute of Environmental Health Sciences (ES011195, ES009047). The authors report no conflicts of interest. 
sites, DNA binding regions of transcription factors, post-translational modifications affecting protein structure, distribution and activity, and targeted, hypothesis-driven studies linking the chemistry and biochemistry of thiols to oxidative stress, redox signaling, nitric oxide signaling, zinc regulation, aging and a host of disease processes. The large number of research studies makes it impractical to provide a comprehensive review on all of the thiol/ disulfide redox systems. At the same time, the common reactivities of thiols with oxidants and central roles of redox sensing and signaling necessitate efforts to understand function of individual components within intact functional cells and organism. During recent years, studies of integrated functions of complex systems has flourished through development of systems biology, with 51,472 publications providing conceptual and practical development of ways to assemble, interrogate and understand the interactive functions of components of complex systems. Among this wealth of scientific papers, however, only 122 citations are retrieved for "thiol and redox systems biology". The incomplete genealogy (Fig 1) points to an opportunity for contemporary science to assemble the extensive detailed knowledge of thiol systems into integrated redox systems biology models.

Occam's razor directs simplification to minimal components. In application to thiol systems, this approach has encouraged generalizations that sometimes oversimplify behavior of thiol systems. Protein thiols exist in a range of aqueous and non-aqueous environments and in proximity to charged amino acid and different metal ions. Perhaps most importantly, the mammalian genome encodes a limited number of protein thiols, and crystallography, NMR spectroscopy and detailed molecular and chemical studies provide considerable knowledge for many of these (Sali et al., 2003). Science is poised to assemble systematic knowledge of the thiol proteome, and systems biology provides tools to develop integrated models of their reactivities and functions in complex systems (Kemp et al., 2008). The task is daunting, yet now approachable because of the availability of genomic and proteomic databases (e.g., http://www.biochemweb.org/databases.shtml) powerful analytical tools, bioinformatics (e.g., http://drcat.sourceforge.net/drcatindex.html) and pathway and functional network analysis tools (www.genego.com, www.ingenuity.com).

In the present review, we summarize thiol/disulfide redox states as a basis for improved understanding of redox signaling and control. We do not explicitly address enzyme active sites as these are better addressed in terms of the specific reactions and catalytic mechanisms. The review largely addresses mammalian systems, with consideration of other metazoans only in terms of evolution of the redox proteome. Because of the vast literature and availability of reviews, we focus on thiols as components of more complex redox systems and principles that the cysteine proteome has co-evolved with the complexity of organisms, exists in redox circuits that are kinetically controlled, and has semi-autonomous redox hubs controlling redox systems in different subcellular compartments. Important new insights provided by mass spectrometry-based redox proteomics are reviewed, and the implications of advances in redox systems biology to understanding effects of oxidative stress in complex biological systems are discussed. Finally, to illustrate the utility of systems biology approaches to understanding mechanisms of disease and toxicity, biological responses to the widespread environmental toxicant, cadmium $(\mathrm{Cd})$ are reviewed. The development of tools to investigate the integrated nature of redox systems suggests 
opportunities for rapid progress in development of redox systems biology models of health and disease.

\section{Fundamental concepts}

All redox signaling and control functions operate within the physical and chemical constraints of the cell. In general, this means that the thermodynamic limits are defined by the redox potential $\left(\mathrm{E}_{\mathrm{h}}\right)$ of the $\mathrm{NADP}^{+} / \mathrm{NADPH}$ couple and the $\mathrm{O}_{2} / \mathrm{H}_{2} \mathrm{O}$ couple, where the redox potential provides a measure of the tendency of the couple to accept or donate electrons. The difference in $E_{h}$ values between two couples is proportional to the free energy for electron transfer $\left(\Delta \mathrm{G}=-\mathrm{nF} \Delta \mathrm{E}_{\mathrm{h}}\right.$, where $\mathrm{n}$ is the number of electrons transferred and $\mathrm{F}$ is Faraday's constant). $\mathrm{E}_{\mathrm{h}}$ is dependent on both the inherent tendency of the chemical to accept or donate electrons, expressed in the standard potential $\left(\mathrm{E}_{\mathrm{o}}\right)$, and also the concentrations of the acceptor (oxidized) and donor (reduced) species of the couple, as defined by the Nernst equation $\left\{\mathrm{E}_{\mathrm{h}}=\mathrm{E}_{\mathrm{O}}+\mathrm{RT} / \mathrm{nF} \ln\right.$ ([oxidized]/[reduced]) $\}$. The energetics of electron transfer is dependent upon the $\mathrm{pH}$, which requires use of the appropriate $\mathrm{E}_{\mathrm{o}}$ value to reflect the $\mathrm{pH}$ where the reaction occurs. Although these are defined as equilibrium values referenced to a standard hydrogen electrode, biological systems are not at equilibrium and must always be considered steady-state estimates. In biological systems, the steady-state $\mathrm{E}_{\mathrm{h}}$ for $\mathrm{NADP}^{+} /$ NADPH is in the range of $-400 \mathrm{mV}$ while the $\mathrm{O}_{2} / \mathrm{H}_{2} \mathrm{O}$ couple is about $+600 \mathrm{mV}$, providing the biological limits for redox signaling and redox sensing. Thiol/disulfide systems undergo reversible reactions under a narrower range, typically between -400 and $0 \mathrm{mV}$.

The steady-state $E_{h}$ values provide convenient measures of the response characteristics of redox-active elements in biological systems, but these values do not provide information about the kinetics of the reactions. This issue is of fundamental importance as it provides a major impetus for development of redox systems biology. The mammalian genome encodes 214,000 Cys residues, at least 10-20\% of which are redox-active under biologic conditions. In the context of a non-equilibrium steady state in which $\mathrm{O}_{2}, \mathrm{H}_{2} \mathrm{O}_{2}$ and other oxidants are present, each of these Cys residues exists in a partially oxidized state, determined by the relative rates of oxidation, the counterbalancing reduction by NADPH-coupled systems, and the usually slow thiol-disulfide exchange reactions $\left(20 \mathrm{M}^{-1} \mathrm{~s}^{-1}\right)$ with cysteine/cystine (Cys/ CySS), GSH/GSSG and other proteins. The total protein thiol pool in cells is $10-40 \mathrm{mM}$, so the steady-state $\mathrm{E}_{\mathrm{h}}$ of individual protein Cys residues present at $1 \mu \mathrm{M}$ to $1 \mathrm{fM}$ can be a complex function of reaction rates with oxidants, reductants and other proteins.

The importance of this for the evolution of biologic functions can be considered in terms of the consequences of combining rate constants with protein abundance. The rates of reaction of protein thiols with $\mathrm{H}_{2} \mathrm{O}_{2}$ varies over 6 orders of magnitude (Nagy and Winterbourne, 2010). The concentration of proteins similarly ranges over at least 6 orders of magnitude, as indicated above from about $1 \mu \mathrm{M}$ to $1 \mathrm{fM}$ or lower. In consideration of these ranges, it becomes apparent that there are two possible orders of interaction, with rate constants varying in proportion to protein abundance and with rate constants varying inversely with protein abundance. In the former, $10^{7} \mathrm{M}^{-1} \mathrm{~s}^{-1} \times 10^{-6} \mathrm{M}=10 \mathrm{~s}^{-1}$ and $10 \mathrm{M}^{-1} \mathrm{~s}^{-1} \times 10^{-12} \mathrm{M}=$ $10^{-11} \mathrm{~s}^{-1}$. In the latter, $10^{7} \mathrm{M}^{-1} \mathrm{~s}^{-1} \times 10^{-12} \mathrm{M}=10^{-5} \mathrm{~s}^{-1}$ and $10 \mathrm{M}^{-1} \mathrm{~s}^{-1} \times 10^{-6} \mathrm{M}=10^{-5}$ $\mathrm{s}^{-1}$. Thus, the simple scaling of reaction rates with abundance provides means to maintain a 
stable, non-equilibrium state of redox components (latter case) while at the same time containing elements which can be regulated to provide effective on-off switching for cell signaling (former case).

Differential scaling of reaction rates and abundance of reactive elements is further specialized in biologic systems by subcellular compartmentation and microcompartmentation. Organelles provide membrane-limited compartments that are often specialized in redox activities, e.g., mitochondria and chloroplasts have electrochemical mechanisms for ATP production, peroxisomes are enriched in $\mathrm{H}_{2} \mathrm{O}_{2}$ linked metabolism, the secretory pathway has oxidative systems for sequential processing of proteins for the cell surface and secretion. Microcompartmentation refers to heterogeneity in solute distribution within volumes not bounded by membranes. With diffusion coefficients of solutes in aqueous systems, solute heterogeneity exists in biological systems only for solutes with turnovers exceeding about $2 \mathrm{~s}^{-1}$ (Jones et al., 1990). As evident from the approximations above for rate constants and abundances of proteins, effective redox signaling that is requires relatively high rates of reaction and high abundance elements; these are achieved in association with membranes and signaling complexes (D'Autreaux and Toledano, 2007).Finally, a new concept was introduced recently that there is a need to discriminate "redox signaling" thiols from "redox sensing" thiols (Jones, 2010). Redox-sensing thiols are defined as elements in a global redox control system that utilizes redox mechanisms to integrate activities of different biologic systems in a context-dependent manner without changing mechanisms. In this way, a change in central redox elements, such as oxidation of $\mathrm{E}_{\mathrm{h}} \mathrm{GSSG}$ during transition from cell division to differentiation to apoptosis, allows coordinated changes in activity of multiple biologic elements. The central argument for considering redox sensing as something distinct from redox signaling is that only a small fraction of the 214,000 Cys encoded in the human genome appear to function in redox signaling, yet most Cys are highly conserved in metazoan evolution, a large fraction exist in partially oxidized states and most biological functions are dependent upon the redox states of constituent thiols.

\section{Thiols and disulfides in biological systems}

\section{Thiols}

Glutathione (GSH)-The most abundant thiol in mammalian systems is glutathione (GSH), present at about $10 \mathrm{mM}$ in liver and kidney (Yuan and Kaplowitz, 2009, Lash, 2009) but varying to low micromolar concentrations in plasma [e.g., about $2 \mu \mathrm{M}$ in humans, (Jones and Liang, 2009)]. This span of nearly four orders of magnitude emphasizes that activities ascribed to GSH must be considered in the context of the respective abundance of GSH. Enzyme activities are determined by the GSH concentration relative to the enzymatic $\mathrm{K}_{M}$ for GSH, and non-enzymatic rates are proportional to concentration. In terms of specific compartments, GSH in alveolar lining fluid (Moss et al., 2000, Yeh et al., 2007) is >100 times the concentration in plasma; GSH in liver and kidney is 10-fold higher than small intestinal enterocytes (Aw and Williams, 1992, Aw et al., 1992).

Cysteine (Cys) - Although there are five times more papers on GSH than the more general term "thiol", GSH is never the only thiol in redox systems. In human plasma, the 
major low molecular weight thiol is cysteine, present at about $10 \mu \mathrm{M}$ (Jones et al., 2000). Despite this relatively low concentration, plasma Cys maintains interorgan balance of GSH (Taniguchi et al., 2008, Ookhtens and Kaplowitz, 1998) and protein synthesis (MoriartyCraige and Jones, 2004). Comparison of the rates of Cys use for protein synthesis and GSH synthesis shows that the former can predominate (Anderson et al., 2007). Cys is synthesized from Met through the transsulfuration pathway. In many experimental systems, the rate of GSH synthesis is limited by Cys availability. Under many conditions, variation in Cys availability is associated with variation in GSH abundance. This has been most extensively studied in association with chemical toxicity and chemical carcinogenesis, where adverse effects are potentiated by limited Cys and GSH, but is also evident as part of the diurnal variation entrained by the timing of consumption of the sulfur amino acids, Met and Cys.

Protein thiols-In plasma, the concentration of protein thiol is much higher than either Cys or GSH, i.e., in the range of 200 to $500 \mu \mathrm{M}$ (Chawla et al., 1984), principally due to serum albumin. Tissues also contain higher total protein thiol than low molecular weight thiols, often in the range of 10 to $40 \mathrm{mM}$. Individual high abundance proteins in cells can contribute thiol concentrations similar to that for albumin in plasma, while concentrations of many individual peptidyl Cys are in the low micromolar range. For instance, if total protein thiol were $20 \mathrm{mM}$ and 1000 proteins containing an average of 10 Cys contributed to most of these thiols, then the average concentration of specific protein thiols would be $2 \mu \mathrm{M}$.

Other low molecular weight thiols-For more complete systems models, other lowmolecular weight thiols in extracellular fluids and cells also need to be incorporated. The precursor-product relationship of Cys and GSH provides a well-studied example of the importance of interactions. In humans, both Cys and GSH undergo diurnal variations linked to dietary intake of sulfur amino acids, yet the precursor-product relationship maintains these systems out of phase by $7 \mathrm{~h}$ (Blanco et al., 2007). In human plasma, homocysteine (HCy) is present at about $2 \mu \mathrm{M}$ (Elshorbagy et al., 2008), a concentration comparable to that for GSH; total $\mathrm{HCy}$, consisting of all of the forms in plasma, have been associated with cardiovascular disease (Refsum et al., 1998). However, uncertainties exist concerning mechanisms because concentrations of thiol and disulfide forms vary in association with methionine metabolism and interactions with other thiols and disulfides in the plasma (Mansoor et al., 1992). Systems approaches to model HCy formation and loss, along with HCy transport and oxidation-reduction reactions with other thiol/disulfide systems will be required to understand these complex interactions. The critical need for such integrated redox systems approach is evident from the failure to understand the mechanisms underlying association of total plasma HCy with cardiovascular disease despite decades of highly targeted research.

Mechanistic understanding of individual thiols similarly requires consideration of other thiol/disulfide systems. Cys concentration in cells is in the range of 50 to $150 \mu \mathrm{M}$ and can determine synthesis rates of GSH (Lu, 1999, Deneke and Fanburg, 1989) but also vary independently of GSH (Jones et al., 2004). Importantly, Cys is required for synthesis of short-lived proteins so that impacts on GSH synthesis probably do not occur without impacts on these proteins. Coenzyme A (CoASH) is another important cellular thiol that is rarely 
considered in functional studies. CoASH is present at about $80 \mu \mathrm{M}$ (Crane et al., 1982) and is required for the citric acid cycle and $\beta$-oxidation of fatty acids in mitochondria and also for fatty acid biosynthesis associated with the endoplasmic reticulum. Crane et al showed that CoASH concentration declines in association with GSH loss in oxidative stress, clearly establishing that these thiols can vary together. The CoASH precursor, pantotheine, is rarely studied but can, in principle, limit CoASH availability. The data point to a need for quantitative models to incorporate $\mathrm{HCy}, \mathrm{CoASH}$, and other central thiol components along with GSH, Cys and redox-active protein thiols to enhance understanding of functional determinants in complex systems.

\section{Disulfides}

Disulfide concentrations often vary in association with changes in corresponding thiols in biologic systems, and this is rarely addressed in a rigorous manner. Instead, oxidative stress research often shows that measured thiol and disulfide concentrations are not fully consistent with the expected stoichiometry for thiol oxidation to disulfide. Frequently, results show a decrease in thiol with no increase in disulfide or an increased disulfide without decrease in thiol. Such results can occur as a consequence of loss of thiols due to reaction with electrophiles generated through lipid peroxidation. In such cases, discussion of thiol/disulfide ratio rather than concentrations of thiol and disulfide allows conclusions concerning oxidative stress. Such simplified interpretations can be misleading because they ignore the reaction products derived from the electrophiles and do not provide mechanistic interpretations specifically linked to thiol, disulfide, thiol/disulfide ratio or $\mathrm{E}_{\mathrm{h}} \mathrm{GSSG}$ (Hansen et al., 2004, Kirlin et al., 1999).

In many systems, adaptive responses allow a pool size effect where the abundance of GSSG is positively correlated with the concentration of GSH. This is consistent with a steady-state balance in which GSH conversion to GSSG, determined by GSH concentration, is adjusted to the steady-state rate of GSSG conversion to GSH by GSSG reductase, determined by GSSG concentration (Sies and Summer, 1975, Gilbert, 1990a). However, because GSH and GSSG export from cells can occur with different kinetics (Ookhtens and Kaplowitz, 1998) and GSH can be biosynthesized but GSSG is only derived from GSH, GSSG does not vary with GSH in a simple, linear manner. Furthermore, GSSG reacts with Cys to form CySSG (Jones et al., 2000, Reed et al., 1983) and with protein Cys to covalently modify proteins (Mieyal and Chock, 2012). Integrated systems approaches including all of the components within computational models can considerably clarify the dynamics of such complex systems (Kemp et al., 2008).

\section{GSH/GSSG ratio and GSH/GSSG redox potential}

As one extends consideration to include dynamic changes of redox systems during biologic transitions, such as during development, apoptosis or environmental challenge, additional issues of concomitant variation in multiple redox elements become evident. Gilbert (Gilbert, 1990a) considered these issues in detail over 20 years ago, concluding that concomitant variations of GSH and GSSG can have different biological meanings. For instance, if one considers the GSH/GSSG half-reaction, $2 \mathrm{GSH} \leftarrow \rightarrow \mathrm{GSSG}+2 \mathrm{e}^{-}+2 \mathrm{H}^{+}$, one can readily see that both the ratio of GSH/GSSG and the steady-state GSH/GSSG redox potential vary 
with both GSH and GSSG. If a protein disulfide is reduced by 2 GSH to a protein dithiol form, then the energetics of the reaction are determined by $E_{h}$ of the GSH/GSSG couple. On the other hand, if a protein has a single thiol and undergoes the reaction, Protein-SH + GSSG $\leftarrow \rightarrow$ Protein-SSG + GSH, then the system is best described in terms of the ratio of GSH/GSSG (Gilbert, 1990a). Gilbert (Gilbert, 1990a) showed that these can be readily distinguished graphically.

Both monothiol and dithiol systems occur simultaneously in cells, so a single descriptor can never suffice. A change in GSH concentration without a change in GSSG has an associated change in the ratio, GSH/GSSG, and also in the redox potential, $\mathrm{E}_{\mathrm{h}}$, for the GSSG/2GSH redox couple. In mechanisms, the rate of GSH transferase depends upon GSH concentration, while the S-glutathionylation/deglutathionylation of proteins by glutaredoxin depends upon the GSH/GSSG ratio (Gilbert, 1990b), integrin-dependent platelet activation depends upon $\mathrm{E}_{\mathrm{h}} \mathrm{GSSG}$ (Essex and Li, 2003), and GSSG reductase depends upon GSSG concentration (Holmgren, 1989). Because different biologic functions depend upon different parameters, there are inherent covariations in thiol systems in complex systems that are difficult to control experimentally. Hence, one arrives at the conclusion that effective descriptions can only be accomplished with models that incorporate responses to GSH, GSSG, GSH/GSSG ratio and $[\mathrm{GSSG}] /[\mathrm{GSH}]^{2}$, i.e., redox systems models. The available data suggest that an additional 100,000 papers on relative changes of GSH are not likely to provide as much clarification for redox biology as a small number of studies providing interactive redox systems models. Such development is in progress, but a considerable gap exists between global models addressing entire cellular systems (Cadenas and Davies, 2000, Adimora et al., 2010) and models for specific redox pathways (Kippner et al., 2011). As addressed below, the spectrum of reactions of thiols to sulfenic acids and higher oxidation states, as well as formation of nitrosothiols and a range of other modified forms, indicates that these must ultimately be expanded to multi-dimensional redox systems models (Kemp et al., 2008).

\section{The cysteine proteome co-evolved with structural and functional complexity of higher organisms}

The availability of genomic data for large numbers of diverse species allows study of thiol redox systems in terms of changes during evolution (Bender et al., 2008, Miseta and Csutora, 2000). This information is readily accessible, largely defines the individual components, and enables study of individual Cys residues in a protein among species, among variants of the same protein within a species and among other amino acid variations within the same protein. In such studies of the evolution of the Cys proteome, Miseta and Csutora (Miseta and Csutora, 2000) found that Cys content in evolution increased with complexity of the organism (Fig 2). This concept, along with data showing that far more Cys are conserved in metazoan evolution than function in active sites and redox signaling, emphasizes the need to discriminate "redox-sensing" Cys from redox-signaling and active site Cys (Jones, 2010) as introduced above. Redox-sensing Cys integrate cell signaling and other biologic functions by providing orthogonal control elements to adjust activity of components without impacting mechanisms of activity (Jones, 2010). 
Along with selenocysteine ( $\mathrm{Sec}$ ), Cys and Met represent the only amino acids in proteins that can be reversibly oxidized. Sec appears to be present in only 25 mammalian proteins and is mostly limited to enzyme active sites (Burk, 2002, Gladyshev and Hatfield, 1999, Kasaikina et al., 2012). In contrast, GenBank protein files indicate that the human genome encodes about 214,000 Cys unique residues and, excluding about 19,800 first Met in sequences, about 172,000 Met residues (Jones, 2008). Met functions in catalytic centers and as an important structural element; a fraction of the Met residues are present as sulfoxides (Stadtman et al., 2005), but there is little systematic knowledge of the occurrence or function of these oxidations. A unique genetic code for mitochondria in which an isoleucine codon is replaced by a Met codon indicates that Met oxidation could protect mitochondria from oxidative damage (Bender et al., 2008, Misiti et al., 2004), but other evidence argues against this interpretation (Sanz et al., 2006, Moosmann, 2011). A relative deficiency in specific details of Met oxidation during physiologic signaling and cellular regulation currently limits redox systems analyses of Met.

Miseta and Csutora (Miseta and Csutora, 2000) compared Cys, expressed as a percentage of total amino acid content, to that expected randomly from the tRNA ${ }^{\text {Cys }} / \mathrm{tRNA}^{\text {total }}$ (random probability is $3.28 \%$ ), and found that Cys is underrepresented in the proteome for all organisms examined, ranging from $0.41 \%$ for Archaea to $2.26 \%$ for mammals (Fig 2A). They found at least 1 Cys in $92 \%$ of mammalian proteins, but at least 1 Cys in only $50 \%$ of Archaea proteins, which they interpreted to indicate an increase in Cys content with evolution of complexity. They supported this interpretation with analysis of ribosomal proteins and found that Cys content increased with complexity of species (Archaea $\rightarrow$ Escherichia coli $\rightarrow$ Yeast $\rightarrow$ Drosophila $\rightarrow$ Human). The ribosomal proteins contained less Cys than expected, indicating a selection against Cys content. Extension to other proteins and other metazoan species confirms this result (Jones, 2010). For instance, the Cys content of both cytoplasmic and mitochondrial ribosomes have this characteristic (Fig 2B). Among specific Cys residues measured in redox proteomics studies, analysis of random subsets shows $>90 \%$ conservation while total amino acid conservation in the same proteins is only about 70\% [Fig 2C, (Go et al, 2012)]. Thus, interpretations of thiol biology must accommodate the knowledge that there is selection pressure against total Cys content, conservation of Cys that are encoded, and increased Cys content associated with evolution of organism complexity.

Further insight into redox organizational structure is likely to be obtained from extension of the concepts developed by Miseta and Csutora. For instance, thiol reactivity toward $\mathrm{O}_{2}$ indicates that changes in evolutionary pressure could have occurred with transitions impacting oxygenation. One can hypothesize that selection against Cys would have occurred unless protective mechanisms coevolved, such as Zn binding, or the Cys proteome evolved to provide a selective advantage to exposure to increased $\mathrm{O}_{2}$. Evolution of peroxideproducing and peroxide-metabolizing systems may have allowed co-evolution of the Cys proteome through altered constraints in organisms possessing these activities. Finally, as discussed below, eukaryotic organelles maintain different thiol/disulfide redox characteristics, and oxidation/reduction of protein Cys residues has a mechanistic function in protein trafficking and regulation. Extension of the concepts of Miseta and Csutora to consider evolution of the Cys proteome in conjunction with the origin of specialized 
compartmental structures and functions can be expected to provide additional insight into physical organization structure-function relationships.

\section{The Cys proteome supports multiple biological functions}

As illustrated by the genealogy of thiol redox systems biology (Fig 1), Cys residues in proteins not only function in multiple biologic processes, but also in multiple types of chemical modifications. While oxidation during relatively severe oxidative stress and toxicity have received considerable attention, reversible modifications of single and vicinal Cys are well known to provide biological switching mechanisms [(Forman et al., 2009, Schafer and Buettner, 2001, Brandes et al., 2009), Fig 3]. Single Cys are oxidized to sulfenic acid and also to disulfides with GSH, Cys, homocysteine ( $\mathrm{HCy}$ ). Cys residues are often considered in terms of "on-off" switching mechanisms in redox signaling, but this multiplicity of chemical modification provides a "change of meaning" switching mechanism that also allows for a specific Cys residue to serve as a system conversion switch.

Although sulfenic acid is a relatively unstable oxidation product, Cys sulfenic acids can be stabilized in isolated form in protein tyrosine phosphatase 1B as an internal sulfenamide with a proximal amine (Tonks, 2005); although reaction kinetics prevent this from occurring in cells during signaling, the structure illustrates that even highly reactive intermediates can exist in biologic systems. Such stable structures, as well as glutathionylation to introduce a negative charge, cysteinylation to convert to a zwitterion, and acylation to convert to a lipophilic site, provide a range of structural changes that change binding properties (Fig 3). Reversible reaction with aldehydes, including monosaccharides, to form thiolhemiacetals, can also occur but whether such modifications have biological functions is not known. Several proteins have Cys residues that undergo different modifications (Mallis et al., 2001, Haendeler et al., 2002, Hashemy and Holmgren, 2008, Casagrande et al., 2002, Reynaert et al., 2006, Ishima et al., 2007) so that corresponding multisignaling functions will require models in which the number of dimensions is expanded to accommodate the multiple mechanisms.

Many proteins contain vicinal Cys residues that form internal disulfides upon oxidation. As with the energetics of thiol/disulfide systems where the 2:1 stoichiometry of 2GSH per GSSG differs from that for the 1:1 couple, NADPH and $\mathrm{NADP}^{+}$, the reactivities and functions of vicinal dithiols follow different principles than monothiols. In human thioredoxin-1 (Trx1), Cys73 has different susceptibility to modification than nearby Cys62 and Cys69, and modification of the former impacts Trx1 activity differently than that oxidation of the Cys62, Cys69 pair (Watson et al., 2003b). Many dithiol structures exist as metal clusters, some of which reversibly bind metals. Binding of $\mathrm{Zn}^{2+}$, for instance, can stabilize vicinal thiols against oxidation, and oxidation can result in release of $\mathrm{Zn}^{2+}$. Alternatively, $\mathrm{Zn}^{2+}$ binding to vicinal thiols in the regulatory domain of protein kinase $\mathrm{C}$ alpha or beta greatly increases their reactivity to hydroperoxides. In glutaredoxin-2, $\mathrm{Fe}^{2+}$ is bound in an iron-sulfur cluster in an inactive form (Lillig et al., 2005). Oxidation causes release of $\mathrm{Fe}^{2+}$ and activation of enzymatic activity. Glutaredoxin provides connectivity between monothiol and dithiol systems, yet the differences in reactivities and functions of dithiol and monothiols requires complex models to effectively integrate their functions. 
Complex systems models are also needed to incorporate competing modifications of Cys residues, such as nitrosylation by NO (Anand and Stamler, 2012, Nakamura and Lipton, 2011) and sulfhydration by $\mathrm{H}_{2} \mathrm{~S}$ (Mustafa et al., 2009, Gadalla and Snyder, 2010). Unlike modifications that function through conformational change, nitrosylation can function to provide a nitroso donor (Martinez-Ruiz and Lamas, 2004) and sulfhydration can serve as a sulfane donor (Li et al., 2011). These systems occupy the same physical and chemical space and can involve the same Cys residues as oxidative changes. However, these are distinct in that they not only result in conformational changes but also support transfer reactions. Together, the spectrum of Cys modifications strongly emphasizes the need for systems models that can incorporate overlapping and competing functions of thiol systems. Although difficult to visualize, computational methods allow integration of alternative sulfoxidation, glutathionylation, cysteinylation, nitrosylation, sulfhydration and vicinal disulfide formation within a single redox system.

\section{Kinetic limitations in thiol redox systems}

Extensive use of thermodynamic concepts of redox potentials has perhaps obscured the central observation that most thiols exist under kinetically controlled steady-state conditions (Jones et al., 2000, Kirlin et al., 1999). A previous review on non-equilibrium thermodynamics of thiol-disulfide systems considered many key issues and provided an initial perspective on development of redox systems biology (Kemp et al., 2008). Research was summarized showing that thiol/disulfide systems are not in equilibrium in biologic systems, i.e., 1) GSH/GSSG in liver is not in redox equilibrium with NADPH/NADP ${ }^{+}$(Sies and Summer, 1975), 2) Cys/CySS in plasma is not in redox equilibrium with GSH/GSSG in plasma (Jones et al., 2000), 3) Cys/CySS and GSH/GSSG change differently with age (Jones et al., 2002), 4) GSH/GSSG is not in equilibrium with Trx-1[(-SH) $)_{2} /$-SS-] in cells (Miller et al., 2002), 5) GSH/GSSG changes with cell differentiation but Trx-1[(-SH) $)_{2} /$-SS-] does not (Nkabyo et al., 2002) and 6) Cys/CySS in cells is not in equilibrium with GSH/GSSG (Jones et al., 2004). Reviews addressing kinetics of redox machinery in the periplasmic space of bacteria (Kadokura and Beckwith, 2010), secretory pathway in antibody production (Cenci and Sitia, 2007, Cenci et al., 2011), mitochondrial import pathway and endocytosis (Zhong et al., 2008, Kamga et al., 2010) are also available. The concepts developed in the Kemp review provide a framework to construct models in which central redox control nodes are defined and the activities of the individual components are used to explore the complex relationships of the components and their responses to challenges. Complementing the specific compartmentalized functional pathways in protein processing, the review summarizes thiol/disulfide pathway, redox potential, and rate information as a basis for kinetic modeling of sulfur switches that function in redox signaling. This addition is important because movement of proteins between compartments is inherently "nonequilibrium" by virtue of a unidirectional nature, while redox signaling in a scalar compartment does not necessarily have that character.

A redox system in steady state (i.e., control cells at rest) may have the appearance of being at equilibrium, when it is not. Perturbation of a stable non-equilibrium system results in deviation and return to the steady state with characteristics as observed for perturbation of an equilibrium system (Kemp et al., 2008). Two examples illustrate the point. GSH is often 
discussed as a "redox buffer" to protect proteins from oxidation. GSH does, in fact, protect proteins from oxidation, but this is not equivalent to "buffering" in the sense that the bicarbonate/ $\mathrm{CO}_{2}$ system buffers against a $\mathrm{pH}$ change. Redox buffers have been used to study protein folding (Lyles and Gilbert, 1991) and cellular responses to variation in redox state (Go and Jones, 2010a), but these are in vitro conditions used to mimic in vivo conditions. Under normal physiologic conditions, the GSH system "buffers" against oxidation by providing a kinetically efficient means to eliminate oxidant and not by rapid equilibration with proteins. Rapid equilibration with proteins requires a catalyst, as shown by studies to develop redox-sensitive forms of green fluorescent protein (Gutscher et al., 2008, Dooley et al., 2004, Hanson et al., 2004), although equilibrium in microcompartments can also occur (Morgan et al., 2012). A second example is the "floodgate" hypothesis, namely that peroxiredoxins are hyper-oxidized to allow a sustained oxidant activity during redox signaling (Low et al., 2007). The image conjured by the model is that a floodgate keeps out the massive sea, i.e., that the cytoplasm is a massive redox-buffered system. A more accurate image probably should be that of a valve regulating a spillway, controlling entry of reducing equivalents into a non-equilibrium system. Studies of steady-state oxidation of the mitochondrial systems, including the Trx2 system (Chance, 1954, Chance, 1952, Roede et al., 2012) and also cytoplasmic/nuclear systems, including the Trx 1 system (Go et al., 2007, Jones, 2008, Sies and Summer, 1975) show that these pathways exist in a kinetically limited state. Electrons are always flowing through these redox systems, but the rates of electron flow are not sufficient to maintain complete reduction against ongoing oxidative reactions. While this difference may appear trivial, there is a fundamental difference because the former presents an image of bulk thiols being equilibrated to a highly reducing potential while the latter depicts bulk thiols as part of an interacting steady-state redox system. The former carries the implication that only a small fraction of thiols are biologically important; the latter is consistent with the evolution of the Cys proteome among metazoans, namely, that most protein Cys residues are conserved.

The Kemp review also considers kinetic models and potential mechanisms for control of non-equilibrium steady states, identifying gaps in knowledge especially related to redox communication between compartments and definition of redox pathways. Electron transfer rates between specific components within biologic systems can vary considerably, but the overall rates are ultimately dictated by the rates of transfer to $\mathrm{O}_{2}$, the terminal electron acceptor for aerobic organisms. The rates for mitochondrial electron transfer are orders of magnitude greater than oxidative reactions involving thiol systems (Jones, 2006), underscoring the need for effective insulation of thiols from high-flux electron transfer systems. In mammalian cells, total peroxidase activity is greater than the capacity to reduce $\mathrm{O}_{2}$, and associated with low steady-state $\mathrm{H}_{2} \mathrm{O}_{2}$ concentrations (Jones et al., 1981). Because of the relatively slow rates of protein thiol oxidation with low $\mathrm{H}_{2} \mathrm{O}_{2}$, most thiols remain in a relatively reduced steady state (Go et al., 2011, Leichert et al., 2008, Sethuraman et al., 2004), but the rates of oxidation of specific thiols vary over several orders of magnitude (Winterbourn and Metodiewa, 1994).

In the steady state, thiols undergo oxidation due to increased oxidant, such as $\mathrm{H}_{2} \mathrm{O}_{2}$ produced by NADPH oxidase. Under these conditions, access to oxidant selectively oxidizes locally accessible and more reactive thiols to provide specificity in signaling (D'Autreaux 
and Toledano, 2007). Systems models are needed with 3-dimensional formulations that account for changes in concentrations of redox-active components both in time and in space. Consequently, terms for sequestration and release of redox-active components, as well as oxidant generation and removal, need to be included. Importantly, the available data and interpretation that relatively small changes in local flux perturbs redox steady states in signaling indicate that oxidants other than $\mathrm{H}_{2} \mathrm{O}_{2}$ could provide redundancy in signaling (e.g., metal ion, cystine/cysteine, quinone/catechol) and/or that redox signaling could be activated by sequestration/release mechanisms within microcompartments without any net change in electron transfer rates. Systems models provide means to evaluate such possibilities in the absence of tools with resolution for experimental tests.

\section{Definition of thiol redox circuits: components and organizational structures}

\section{Key components}

Key components to define thiol redox circuits are summarized in Table 1 and discussed below. Many studies have evaluated bulk cellular protein thiol content and/or specific protein thiol content in studies where GSH was measured after experimental challenge. Results are consistent with 3 interpretations: 1) GSH and protein thiols have similar response patterns, as shown for $\mathrm{H}_{2} \mathrm{O}_{2}$-treated monocytes (Watson et al., 2003a); 2) GSH is relatively more sensitive, as shown for copper and iron toxicities (Hansen et al., 2006); and 3) specific protein thiols (e.g., Trx1 and Trx2) are more sensitive than GSH, as shown for EGF and TNF-a cell signaling (Go et al., 2004, Halvey et al., 2005) and in response to cadmium and arsenic toxicities (Hansen et al., 2006). The most salient interpretation is that GSH and protein thiol systems function as parallel and non-redundant systems that have overlapping functions (Zhang et al., 2007). Experimental evidence further shows that membranal barriers separate redox compartments and need to be incorporated into the redox organizational structure. Steady-state $\mathrm{E}_{\mathrm{h}}$ for thioredoxin and glutathione systems are not equilibrated, and these systems appear to interact with different subsets of protein Cys (Le Moan et al., 2006) so that individual networks dependent upon each must be considered; we term these "redox regulons" in analogy to genetic concepts of regulons as groups of genes regulated by one protein [for instance, see (Permina et al., 2012)]. Recent data also support the concept that steady-state peptidyl Cys oxidation is associated with functional networks, suggesting a modular redox structure. While incomplete in conceptual development, these considerations of redox pathway organization and redox functional organization provide a framework to begin development of more complete redox systems biology models.

\section{Hierarchical network structures}

Metabolism appears organized in hierarchical structures (Barabasi, 2009). For redox systems, a bilateral hierarchical structure would appear needed to accommodate both reductant and oxidant systems (Fig 4). Two types of redox network structures have been discussed based upon available data (Jones, 2010). One involves parallel branching pathways in which protein Cys residues are effectively isolated, either physically or kinetically, so that they can be modeled as specific substrates of single oxidative and reductive mechanisms (Jones, 2010). Another involves a branching network in which electron transfer reactions occur with greater rates from hubs to lower level nodes and 
slower rates between the lower level nodes in a hierarchical manner (Jones, 2010). The latter is based upon the scale-free hierarchical clustering concepts of Barabasi which obey a power law (Barabasi, 2009, Karsai et al., 2012). This organizational structure has an inherent stability and points to a limitation in currently available kinetic data for thiol systems, which are biased toward rate constants for fast interactions. For instance, one can consider Trx 1 reduction of 34 individual Cys in cytoskeleton-associated proteins (Go et al., 2010). The rates of reduction by Trx 1 could be 30 times faster than the rates of the individual Cys with each other or with the GSH system, leading to a correct conclusion that Trx1 is the principal reductant system. Slower interaction of the components with each other, however, ensures that all respond in the same way to a redox change, and a slower reactivity with the GSH system provides a backup system in the event that the Trx 1 system is compromised. Importantly, these depictions of isolated pathways and interactive networks are not mutually exclusive because modules of Cys residues of both types appear likely.

If the Cys proteome has evolved with such an organization, then a bilateral hierarchical scale-free system could account for control of steady-state redox of each of the 214,000 individual protein Cys using known redox systems (Fig 4). Subcellular compartmentation provides two levels of control because both reductants and oxidants have different distributions among compartments. At least 8 compartments can be delineated (cytoplasm, nucleus, mitochondria, endoplasmic reticulum, Golgi, lysosome, peroxisome, extracellular space), meaning that at least 64 different combinations of reductants and oxidants can occur. Within each compartment, multiple primary reductants are present. These include NADPH and NADH; NADPH appears to be the primary reductant for thiol redox control through central "reduction hubs", i.e., nodes that serve as upstream sources of reducing equivalents.

At least two of these are present in major cellular compartments, thioredoxin reductase and GSSG reductase. Thioredoxin reductase can reduce multiple proteins, and its most studied substrate, thioredoxin, reduces hundreds of protein Cys residues (Holmgren, 1989). Some evidence indicates that alternative mechanisms are available to reduce thioredoxin (Watson et al., 2008). Importantly, large number of thioredoxin-like proteins containing CXXC motif have been described (Jeong et al., 2009) and these can support other branches in a hierarchical structure. GSH can similarly function in reduction of hundreds of protein Cys residues mediated by glutaredoxins. Each of these can be considered as "redox regulons", e.g., Trx1 regulon is not identical to the GSH regulon, and definition of these regulons will improve description of systems functions. It must be emphasized that this is proposed as a conceptual framework to address a very complex problem; there is little experimental evidence to clarify whether models should be developed with separate redox regulons for $\mathrm{NADH}$, thioredoxin reductases, thionein or other redox active components.

One may note that in a hierarchical scale-free structure, there can be an advantage to redox hubs NOT having absolute specificity because off-target redox activities at slower rates provide a backup mechanism to maintain functions when there is a failure of the primary system. An early example is provided by the discovery of glutaredoxin in studies of deoxyribonucleotide reductase in an E. coli mutant defective in thioredoxin (Holmgren, 1979). Multiple other proteins with redox activities are known, e.g., nucleoredoxin (Funato and Miki, 2007) and thionein (Sagher et al., 2006), and these provide additional branches 
within a hierarchical structure. Additional secondary redox systems have also been characterized, such as redox factor-1 reduction of transcription factors (Xanthoudakis and Curran, 1992); these serve as downstream branches in a hierarchical structure.

The multiplicity of this structure (64 compartments $\mathrm{x} 2$ pyridine nucleotide reductants $\mathrm{x} 2$ primary thiol system reductases $\mathrm{x} 25$ thioredoxin-like proteins $\approx 6,400$ ) indicates that a combination of perhaps 5 distinct oxidants operating with 8 secondary oxidant and reductant systems $(6,400$ × 5 × $8 \approx 260,000)$ would provide sufficient components for specific regulation of all 214,000 Cys residues encoded in the human genome. Known oxidants that could support redox regulons include $\mathrm{O}_{2}, \mathrm{H}_{2} \mathrm{O}_{2}$, lipid hydroperoxides, peroxynitrite, cystine, quinones and other low molecular weight chemicals. Secondary oxidants include components of the protein oxidation machinery in the secretory pathway and mitochondrial import, and also protein disulfide isomerases, glutaredoxins, peroxiredoxins, glutathione Stransferases and other proteins operating in oxidative modes. Incorporation of data for individual proteins within redox organizational structures operating under physiologic conditions will support models that are considerably improved over those obtained with high-dose oxidative challenges where bulk protein Cys are simultaneously oxidized. Data from such physiologic conditions will provide opportunities to refine models to gain insight into key control points in redox control mechanisms.

\section{Compartmentation}

An important component of organization of structures in complex organisms involves compartmentation of biochemical processes at multiple levels, from organs (e.g., kidney), to functional units (e.g., glomeruli), to cells (e.g., endothelial cells), to organelles (e.g., mitochondria) to suborganellar structures (e.g., signaling complexes associated with the plasma membrane). As indicated above, high-flux electron transfer reactions are compartmented in the mitochondrial inner membrane. Other structures are also used to contain redox processes, including compartmentation of hydrogen peroxide reactions in peroxisomes, oxidation of lipophilic xenobiotics in the endoplasmic reticulum, and oxidation of proteins for secretion in the cisternae of the endoplasmic reticulum. Such compartmentation allows relatively low-flux redox signaling and control to occur separately in association with the plasma membrane, aqueous cytoplasm, nucleus, and extracellular space while at the same time using higher flux oxidative reactions in other locations.

Trx redox system-Earlier studies on redox compartmentation have been reviewed in detail (Go and Jones, 2008, Jones and Go, 2010) and are only briefly discussed here. The most detailed information on proteins is available for thioredoxin systems, which have been studied in different compartments by measuring specific forms. Results show mitochondrial Trx2 to be maintained at the most reduced steady-state redox potential, ranging from about -360 to $-330 \mathrm{mV}$. The nuclear $\operatorname{Trx} 1(-290 \mathrm{mV})$ is maintained somewhat more reducing than cytoplasmic Trx1 $(-270 \mathrm{mV})$. The characteristics of these have been studied under steady state conditions in cells where precursors of NADPH supply have been limited. Results show that mitochondrial thioredoxin reductase- 2 and peroxiredoxin- 3 become oxidized concurrently with Trx 2 oxidation (Zhang et al., 2007) and cytoplasmic/nuclear thioredoxin-1, redox factor-1 and p50 subunit of NF- $\mathrm{kB}$ become oxidized concurrently with 
Trx1 (Go et al., 2007, Jones, 2008). Consequently, the thioredoxin systems are maintained under kinetically controlled steady states that differ among major subcellular compartments.

GSH/GSSG redox system-The steady-state redox potential of the GSH/GSSG system is more oxidized than the thioredoxin systems, being about -330 to $-300 \mathrm{mV}$ in the mitochondrial matrix and -260 to $-200 \mathrm{mV}$ in the cytoplasm. The values in the cytoplasm are dependent upon the life cycle of the cell, with proliferating cells having more negative steady-state redox potentials and differentiated cells having more positive values. Cells undergoing apoptosis and necrosis have a more oxidized steady-state potential, typically in the range of -170 to $-150 \mathrm{mV}$. Values in the cisternae of the endoplasmic reticulum have been estimated to be in this latter range (Hwang et al., 1992), only slightly more reducing than that in plasma $(-140 \mathrm{mV}$ ) (Jones et al., 2000). Values for the redox potential of GSH/ GSSG in nuclei are not available but appear likely to be somewhat more reducing than cytoplasm based upon protein glutathionylation/protein thiol ratios (Go et al., 2007) and fluorescent indicators (Markovic et al., 2009).

Cysteine/Cystine redox system-The cysteine/cystine redox couple has not been extensively studied in cells. The most complete study (Jones et al., 2004) provided evidence that the system is substantially oxidized relative to GSH/GSSG and thioredoxins in HT29 cells. Because there are limited data, interpretations must be made with caution. The relatively positive redox potential estimates, however, suggest that cystine could be an intracellular oxidant, delivered through regulated uptake by cystine transporters. Recent studies show that regulation of extracellular cysteine/cystine redox potential in cell culture is independent of the GSH system in HT29 cells (Anderson et al., 2007) and mediated by cystine uptake and cysteine efflux systems in $\mathrm{CaCo} 2$ cells (Mannery et al., 2010). In isolated cells from $\gamma$-glutamylcysteine synthetase knock-out mice, cystine reduction was shown to be mediated by $\mathrm{x}_{\mathrm{CT}^{-}}$transport and thioredoxin reductase-dependent reduction (Mandal et al., 2010). Previous research (Mannervik et al., 1983) showed that glutaredoxin and thioredoxin also have slow rates of cystine reduction. The considerable difference between steady-state redox potentials of $\operatorname{Trx} 1$ and cysteine/cystine indicate that cystine reduction by each of these systems is slow relative to Trx1 reduction and cystine uptake rates.

Redox proteomics to define redox networks and pathway maps-Recent studies using mass spectrometry-based redox proteomics provide additional insight into steady-state protein thiol redox states (Go et al., 2011, Leichert et al., 2008, Sethuraman et al., 2004, Le Moan et al., 2006). These studies use isotope-coded affinity tag (ICAT) reagents to measure fractional oxidation of specific peptidyl Cys residues of proteins. For instance, study of HT29 cells under control conditions showed percent oxidation of 641 peptidyl Cys residues from 333 proteins. Median protein thiol oxidation was about $12 \%$ and did not differ substantially between mitochondrial, nuclear and cytoplasmic proteins. Pathway analyses showed that more reduced Cys were in cytoplasmic proteins associated with the cytoskeleton while more oxidized Cys were in cytoplasmic proteins associated with PI3/Akt, Myc-mediated apoptosis and 14-3-3-mediated signaling. Similar redox characteristics for Cys among cytoskeletal proteins is consistent with earlier studies showing an apparent network structure of Cys in actin-associated proteins in which 34 Cys residues responded 
similarly to exposure of endothelial cells to an oxidized extracellular cysteine/cystine redox potential (Go et al., 2010). The results are consistent with a modular redox structure in which the Cys proteome of functional modules, such as the cytoskeleton, co-evolved to provide a homogeneous response to common physiologic challenges. More recently, Truong et al. have developed isotope-coded chemical reporter and acid-cleavable affinity reagents to monitor protein sulfenic acids, which this method can be applied to map oxidized Cys sites and sufenylation of proteins under stress conditions(Truong et al., 2011).

In the nuclei, more reduced Cys were in proteins associated with Ran signaling and RNA post-transcriptional modification while weaker associations of oxidized nuclear proteins occurred with granzyme B signaling (Go et al., 2011). The coverage of nuclear proteins was not as extensive as for the cytoplasm, but together with other published data on nuclear redox proteomics (Go et al., 2011, Go and Jones, 2010b, Go et al., 2009), the results indicate that a number of nuclear redox modules exist (Fig 5). Additional study and resolution of this redox organizational structure will help understand the complexity of redox effects on nuclear import, transcriptional activation and inactivation, DNA replication and repair, RNA processing and export and nuclear protein export and turnover (Fig 5).

In mitochondria, more reduced cysteine residues were found to be in proteins associated with energy metabolism, cell growth and cell proliferation, and weaker associations of oxidized proteins were associated with intermediary metabolism (Go et al., 2011). The results show that steady-state peptidyl Cys oxidation in proliferating HT29 cells has characteristics consistent with dynamic regulation of energy metabolism. The data are too sparse to be able to infer whether multiple Cys residues in multiple mitochondrial systems respond together as a single mitochondrial redox module. Perhaps more likely, multiple mitochondrial redox modules are present and serve to coordinate metabolic adaptations to common energetic and environmental challenges.

The data collectively indicate that specific Cys residues within proteins are associated within functional pathways in subcellular compartments. This provides a framework for consideration of differential protein oxidation during oxidative stress and toxicologic processes because it associates redox response with function. A corollary is that toxic agents could have different effects in differentiated cells and proliferating cells due to differences in steady-state cytoskeletal protein oxidation or to more oxidized steady-states of signaling proteins. Similarly, agents that selectively interfere with the Ran signaling system for nuclear import could differentially impact cell stress responses in proliferating and differentiated cells. Consequently, the results support the interpretations provided above for evolution of the cysteine proteome, multi-dimensional character of Cys modifications and non-equilibrium thermodynamics of thiol systems, indicating that more comprehensive redox systems models will be helpful to understand and test the complex dynamic responses of thiol systems.

Orthogonal control and pathway switching-The bilateral hierarchical redox control structure as described does not incorporate functional aspects related to redox sensing and pathway switching. For redox sensing, components within modules are expected to show parallel responses, but no experimental data are available to test this concept. Similarly, little 
experimental evidence is available concerning pathway switching functions. Leonard et al. (Leonard et al., 2009) found that few Cys undergoing oxidation to sulfenic acid also undergo nitrosylation or glutathionylation. Based upon this, one can speculate that each of the 214,000 Cys has only a small number of physiologically relevant reactions and reaction rates. Assembly of databases documenting modifications in biologic systems will help sort out this organizational structure. In particular, databases containing rate constants for oxidation by $\mathrm{H}_{2} \mathrm{O}_{2}$, cystine, and other prevalent oxidants are needed. Similarly, databases with rates of reduction by thioredoxins and other redox systems are needed. Reaction rates of many protein Cys residues have been determined, but quantitative data for protein abundance are also needed for modeling of kinetically controlled systems. Curated databases are needed to assemble the accumulating redox proteomics data into resources for model development, and this would appear to be possible by addition of new features to existing databases.

\section{Application of redox circuitry concepts to human health and disease}

As indicated by more than 100,000 papers on oxidative stress (Fig 1), redox processes have critical roles in human health and disease. Biomedical research established, however, that supplementation with free radical scavenging antioxidants produced little benefit in several large-scale double-blind interventional studies and led to consideration of non-radical redox systems as central to disease mechanisms [see (Jones, 2006, Jones, 2008)]. Redox systems biology is in a nascent stage of development and will require additional collection of data, such as rate information, as well as improved design of redox organizational structures to understand redox-dependent mechanisms. In this, systems biologists will need to work with experimentalists to improve data collection and build and test models. This interaction is critical because experimental models usually involve sufficiently severe conditions to elicit adverse outcomes in short periods of time while relevant processes in human disease involve less severe conditions and longer durations. Redox systems responses may reflect an adaptability that protects against system failure and disease. Hence, development of redox systems models are expected to be useful for the broad range of disease processes thought to involve oxidative stress, e.g., cardiovascular disease, cancer, lung diseases, gastrointestinal diseases, renal disease, etc., and also a large number of toxicities resulting from environmental and occupational exposures, e.g., cadmium (Cd) exposure, arsenic exposure, ozone, alcohol, cigarette smoke, paraquat, etc. In the following, we provide a summary of research on $\mathrm{Cd}$ as an illustration of application of these concepts to human health.

\section{Cd effects on thiol/disulfide redox system}

\section{Adverse health effects of $\mathrm{Cd}$}

$\mathrm{Cd}$ is a biotoxic nonessential heavy metal that can be taken up by organisms and has been designated as a human carcinogen (Waalkes, 2003). Of concern for Cd, safety is evaluated in terms of urinary $\mathrm{Cd}$ and kidney damage (Noonan et al., 2002) without consideration of possible effects at lower levels on redox signaling and redox sensing mechanisms. Satarug et al (Satarug et al., 2011) recently provided an extensive review of human studies and concluded that "Population data raise concerns about the validity of the current safe intake level that uses the kidney as the sole target in assessing the health risk from ingested 
cadmium". Kidney damage is a relatively severe and late effect (Site, 2000, Klaassen et al., 1999) and more subtle effects on homeostatic mechanisms occur which can have a broad range of adverse health consequences, including increased risk of emphysema and other lung diseases (Lampe et al., 2008), stroke and heart failure (Peters et al., 2010), anemia (Horiguchi et al., 2011), osteoporosis (Gallagher et al., 2008), reproduction (Gerhard et al., 1998, Laudanski et al., 1991), and cancer (Arita and Costa, 2009, Waalkes, 2003). This evidence for toxicity pleiotropy indicates that $\mathrm{Cd}$ must impact multiple systems in different ways. A redox network structure as outlined above suggests how this can occur through impacts on thiol systems that are differentially distributed and controlled during the life cycle of an individual.

Substantial evidence suggests that such differential redox effects are likely to occur at low levels of $\mathrm{Cd}$ that are relevant to human exposures and could contribute to such toxicity pleiotropy. The concepts outlined above indicate that thiol redox effects are likely to occur; the formulation also indicates that both adaptive and maladaptive responses may occur, and these may differ among tissues and life stages. Mouse studies show that renal $\mathrm{Cd}$ reflects long-term exposure but is not correlated with urinary Cd excretion (Thijssen et al., 2007), and human autopsy data show that hepatic cytochrome P450 4A11 (CYP4A11) expression is associated with $\mathrm{Cd}$ in individuals without $\mathrm{Cd}$ exposure in the workplace (Baker et al., 2002). Thus, human population studies and laboratory animal studies support a need for improved means to evaluate responses, health risks and mechanisms of low-level Cd exposure. These issues are relevant to a broad range of toxicology studies in plants, cells and animals (Beyersmann and Hechtenberg, 1997, Deckert, 2005, Waisberg et al., 2003), but in the present brief consideration, we only include effects on thiol/disulfide redox state and signaling in animal cells and tissues.

\section{Regulation of Zn-requiring enzymes by $\mathrm{Cd}$ and $\mathrm{Cd}-\mathrm{Ca}$ interaction}

Cd interrupts the uptake and utilization of other elements resulting in malabsorption of iron, copper and manganese, in increased concentrations of $\mathrm{Cd}, \mathrm{Zn}$ and calcium in the liver and kidneys, in increased phosphorus in the urine, and in iron deficiency anemia. Cd effects on $\mathrm{Zn}$ may be especially important in that $\mathrm{Cd}$ can be substitute for $\mathrm{Zn}$ in a subset of $\mathrm{Zn}$-binding sites. $\mathrm{Zn}$ is required for the activity of over 300 enzymes (McCall et al., 2000) and has an even broader effect due to additional binding sites in the proteome. $\mathrm{Zn}$ binding sites in proteins are made up of the sulfur of cysteine, the nitrogen of histidine or the oxygen of aspartate and glutamate (McCall et al., 2000). The interaction with Cys residues represents a site for disruption of redox networks described above. Cd competes with $\mathrm{Zn}$ for their binding sites on many biologically essential molecules, e.g., DNA damage repair enzymes (Buchko et al., 2000) and metalloproteins, apparently replacing Zn during protein folding rather than displacing $\mathrm{Zn}$ from these molecules. Importantly, $\mathrm{Cd}$ is not redox-active but can stimulate oxidation in some binding sites. Zn-binding sites, such as Zn-finger motifs of transcription factors, regulatory domain of signaling molecules including protein kinase $\mathrm{C}$ (Beyersmann et al., 1994), metalloenzymes such as Cu/Zn-superoxide dismutase (SOD) (Bauer et al., 1980, Huang et al., 2006) and metallothioneins (MT) (Klaassen et al., 1999) are targets for disruption of function by $\mathrm{Cd}$. The effect of $\mathrm{Zn}$ binding to proteins shows diverse outcomes. While there are numerous studies supporting the role of $\mathrm{Zn}$ as being 
protective from oxidation, it has also been shown that $\mathrm{Zn}$ actually enhances redox sensitivity resulting in more susceptibility to oxidation (Maret and Vallee, 1998, Jiang et al., 1998, Crow et al., 1995). The release of $\mathrm{Zn}$ from $\mathrm{Zn}$-requiring superoxide dismutase by $\mathrm{Cd}$ substitution results in inactivation and consequently further disrupts this aspect of redox physiology (Huang et al., 2006).

Additionally, binding of $\mathrm{Cd}$ to albumin occurs in the plasma and can prevent urinary loss of $\mathrm{Cd}$, contributing to the relatively long half-life of $20 \mathrm{y}$ in humans. Albumin is the major protein thiol in plasma and functions to remove reactive electrophiles from circulation. Albumin binding prevents plasma $\mathrm{Cd}$ from being filtered at the glomerulus and competes with MT to form Cd-MT complex. Studies of the interaction between $\mathrm{Cd}$ and $\mathrm{Zn}$ showed 3 main effects, binding to proteins (plasma albumin, macromolecules, MT), interactions at the level of MT induction, and competition for membrane transport (Frazier, 1994).

Environmental metals including $\mathrm{Cd}$ affect biological functions of calcium $(\mathrm{Ca})$. A human study to determine the correlation between $\mathrm{Cd}$ and $\mathrm{Ca}$ showed a significant difference in the average of $\mathrm{Cd}$ concentration of smokers from non-smokers. There was a positive correlation between $\mathrm{Cd}$ and $\mathrm{Ca}$ in the blood of smokers while no correlation between $\mathrm{Cd}$ and $\mathrm{Ca}$ was observed from non-smokers (Zeneli et al., 2010). Moreover, a population-based human study in Europe showed that an increased urinary Cd level was associated with a decreased bone density and height loss (Kazantzis, 2004) supporting the relationship between $\mathrm{Cd}$ and $\mathrm{Ca}$. In vitro and in vivo studies examining $\mathrm{Cd}-\mathrm{Ca}$ interaction have provided evidence that $\mathrm{Cd}$ affects biological function of $\mathrm{Ca}$. The intake of diet with low $\mathrm{Ca}$ resulted in increased $\mathrm{Cd}$ adsorption and accumulation, finally leading to elevation of $\mathrm{Cd}$ toxicity. On the other hand, the large intake of $\mathrm{Ca}$ resulted in decreased $\mathrm{Cd}$ absorption and accumulation, and lowered Cd toxicity (Brzoska and Moniuszko-Jakoniuk, 1998). Similarly, in a rabbit jejunum cell study, Cd inhibited sugar absorption and L-threonine transport when Ca was present in the media (Mesonero et al., 1995, Mesonero et al., 1996). However, this inhibitory effect was not observed if $\mathrm{Ca}$ was not included in the media, suggesting that $\mathrm{Cd}$ and $\mathrm{Ca}$ could have an affinity for the same molecules.

\section{GSH redox system affected by $\mathrm{Cd}$}

Cd interactions with GSH systems are well established (Singhal et al., 1987). As induction of defense mechanisms by Cd, cellular GSH is increased as a consequence of activation of the GSH synthesis enzyme $\gamma$-glutamylcysteine synthetase ( $\gamma$-GCL, (Chen and Goldsbrough, 1994, Mendoza-Cozatl et al., 2005, Satarug et al., 2011, Shukla et al., 2000)). Interestingly, in addition to induction of mechanisms for antioxidants, $\mathrm{Cd}$ also stimulates oxidative stress mechanisms by increasing ROS without Fenton-type reaction association (Thevenod et al., 2000). Therefore, Cd affected GSH synthesis mechanism and ROS generation interferes with the cellular redox state (Ochi et al., 1987, Schutzendubel et al., 2001). Oxidation in $\mathrm{E}_{\mathrm{h}} \mathrm{GSSG}$ due to relatively high Cd exposure $(0.1 \mathrm{mM}, 3 \mathrm{~h})$ was shown in C6 glioma cells although total cellular glutathione level was elevated (Yang et al., 2004). This study supports the notion that activation of Cd-induced oxidative stress is modulated by cellular thiol redox state. A role for Cd-regulated $\mathrm{E}_{\mathrm{h}} \mathrm{GSSG}$ for gene regulation was shown by Hsiao et al. (Hsiao and Stapleton, 2009). Changes in gene expression by low-level $\mathrm{Cd}(4 \mu \mathrm{M})$ in rat 
hepatocytes were affected by cellular GSH redox balance, controlled by BSO and NAC. Additionally, the pivotal role of GSH redox state in Cd-regulated cell growth and DNA synthesis was shown in Chinese hamster V79 cells (Ochi et al., 1987). In this study, Cd (10 $\mu \mathrm{M}, 2 \mathrm{~h}$ ) did not influence superoxide dismutase, catalase, GSH peroxidase or GSSG reductase but resulted in a significant decreased level of GSH, supporting an association of $\mathrm{E}_{\mathrm{h}} \mathrm{GSSG}$ with inhibited cell growth and mechanisms of DNA-synthesis (Ochi et al., 1987).

In addition to GSH redox state, $\mathrm{Cd}$ can impact thiol/disulfide status of Cys residues in proteins. S-Glutathionylation of proteins (Pr-SSG) occurs under a variety of oxidative conditions (Anathy et al., 2012, Giustarini et al., 2004, Mieyal and Chock, 2012, Murphy, 2012, Ziegler, 1985), and glutaredoxin (Grx) is a specific catalyst for the reduction of PrSSG (Gravina and Mieyal, 1993). Acute Cd exposure (3-100 $\mu \mathrm{M}, 30 \mathrm{~min})$ of H9 and Jurkat cells inactivated Grx resulting in inhibition of Pr-SSG reduction and apoptosis (Chrestensen et al., 2000). Cd also inhibited GSSG reductase activity associated with the inhibition of GSH redox regulation systems in both mammalian cells and plants (Chrestensen et al., 2000, Smiri et al., 2011).

\section{Thioredoxin redox system affected by $\mathrm{Cd}$}

$\operatorname{Trx} 1$ and Trx 2 are major cellular oxidoreductases regulating cellular redox homeostasis (Gleason and Holmgren, 1981, Holmgren, 1985) and are sensitive to oxidation by $\mathrm{Cd}$ (Hansen et al., 2006). Thioredoxins reduce oxidized forms of other proteins, as required for deoxyribonucleotide synthesis by ribonucleotide reductase (Arner and Holmgren, 2000, Berg et al., 2002) and reversal of methionine oxidation by methionine sulfoxide reductases (Gonzalez Porque et al., 1970). Proteomics research in yeast showed that both of the major cellular thiol redox systems, GSH and Trx, are essential for cellular defense against Cd (Vido et al., 2001).

Stress response genes, antioxidant systems and metabolic enzymes have been shown to be sensitive to low dose $\mathrm{Cd}$ in in vitro, in vivo, and clinical studies (Bartosiewicz et al., 2001, Conterato et al., 2011, Newairy et al., 2007, Noonan et al., 2002). TrxR1, a selenoprotein controlling the Trx 1 redox system, was induced by Cd in bovine (Sakurai et al., 2005) and human cells (Nishimoto et al., 2006) by enhancing the promoter activity of the 5 '-flanking region of TrxR1 gene (Sakurai et al., 2005). Sakurai et al. also found that Cd-elevated TrxR1 gene expression involves activation of NF-E2-related factor-2 (Nrf2) and its binding to the antioxidant responsive element of TrxR1. Interestingly, a dual function of TrxR1 in cellular responses to Cd was demonstrated in the study using the gene silencing of TrxR1 (Nishimoto et al., 2006). The TrxR1 gene silencing by TrxR1 siRNA elevated cell death by low-dose $\mathrm{Cd}$ (less than $10 \mu \mathrm{M}$ ) compared with control silencing; however, this effect was reversed by high-dose $\mathrm{Cd}$ suggesting that TrxR1 has a dual role in cellular defense mechanisms depending on $\mathrm{Cd}$ concentration. TrxR1 might protect the cells from moderate injury by a low dose of $\mathrm{Cd}$, while it might also potentiate cell death in cells severely injured by high-dose Cd (Nishimoto et al., 2006).

As mentioned above, yeast proteomics data upon Cd exposure are consistent with the gene expression data obtained from in vitro mammalian cells and in vivo animals in response to $\mathrm{Cd}$. Strong induction of proteins by acute $\mathrm{Cd}$ exposure includes molecules associated with 
sulfur amino acid biosynthetic pathways including GSH synthesis, stress responsive heat shock proteins and chaperones, proteases, and antioxidants (Vido et al., 2001). Yeast strains lacking Trx and TrxR showed a Cd hypersensitive phenotype suggesting an important role of the Trx redox system in Cd tolerance (Vido et al., 2001).

Cd-induced toxicity appeared to be mediated by a complex mechanism since $\mathrm{Cd}$ exposure resulted in decreasing antioxidant systems while others show Cd-elevated TrxR expression and increased GSH level and GSH redox system as described above. El-Sharaky et al. found that rats with low dose $\mathrm{Cd}$ ( $2 \mathrm{mg} / \mathrm{kg}$ body weight, 10 days) had induced renal toxicity as results of increasing lipid peroxidation and decreasing GSH level and activity of glutathione peroxidase (GPx) and TrxR (El-Sharaky et al., 2007). A subset of rats treated with selenium and $\mathrm{Cd}$ showed a protective effect from renal toxicity as a result of decreasing lipid peroxidation and total saturated fat and increasing GSH levels and activity of GPx and TrxR. This suggests that seleno-enzymes, GPx and TrxR and their counterpart redox systems, GSH and Trx protect against Cd-induced toxicity (El-Sharaky et al., 2007). Consequently, at the level of individual risk, subpopulations may show selective sensitivity due to nutritional status of selenium.

As indicated, numerous studies support the critical roles of GSH and Trx redox systems for modulating $\mathrm{Cd}$-induced toxicity as consequence of a great affinity of $\mathrm{Cd}$ to thiol groups. However, increasing data also suggest that the accumulation and distribution of $\mathrm{Cd}$ in the various tissues, the interactions of $\mathrm{Cd}$ with other elements, and the damage to tissues caused by $\mathrm{Cd}$ vary due to complex mechanisms depending on many endogenous and exogenous factors including chemical forms, exposure time and doses of Cd (El-Sharaky et al., 2007). These observations support a need for interpretation of data within more complete systems biology models.

\section{Subcellular redox signaling affected by $\mathrm{Cd}$}

Mitochondrial redox signaling affected by $\mathrm{Cd}-\mathrm{Cd}$ binding and oxidation of thiols of proteins is a common component of the molecular mechanisms accounting for most of the biological effects of $\mathrm{Cd}$. $\mathrm{Cd}$ is a well-known stress inducer by disrupting redox signaling and stimulating mechanisms for increasing ROS levels (Cuypers et al., 2010). Cd-complexes penetrate into cells and subcellular organelles including cytoplasm, nuclei, mitochondria, and the endoplasmic reticulum; of these, effects on mitochondrial function may be especially important. A study examining the effects of heavy metals on the major thiol/ disulfide redox systems showed that mitochondrial Trx 2 is oxidized more than cytoplasmic Trx 1 by $10 \mu \mathrm{M} \mathrm{Cd}$, indicating that mitochondrial redox might be more susceptible to Cdinduced disruption (Hansen et al., 2006). This is consistent with other data suggesting that mitochondria are key subcellular targets for Cd (Belyaeva and Korotkov, 2003, Cannino et al., 2009, Early et al., 1992, Tang and Shaikh, 2001), especially due to altered oxidative phophosphorylation (Belyaeva and Korotkov, 2003). Earlier studies with 3.3-40 $\mu \mathrm{M} \mathrm{Cd}$ treatment of isolated rat liver mitochondria showed that lower concentrations stimulated respiration while higher concentrations inhibited respiration (Cameron et al., 1986, Sato et al., 1978). Also, Cd stimulated $\mathrm{NAD}^{+}$-linked mitochondrial dehydrogenase activities and NADH oxidation without stimulation of mitochondrial ATPase activity, indicating direct 
interaction of Cd with NADH dehydrogenase complex or other NADH-dependent enzymes (Cameron et al., 1986). In vivo rat and mouse studies showed that a low dose of $\mathrm{Cd}$ administration caused oxidative damage in liver and kidney with depleted mitochondrial GSH (Nigam et al., 1999) and increased lipid peroxidation in the renal cortex mitochondria (Wang et al., 2010) suggesting that disrupting mitochondrial redox metabolism is associated with Cd-induced liver and renal defects. The broad range of effects indicates that systems biology analyses will be useful to understand the most sensitive low-dose effects and possible differential effects on different organ and cell systems.

Nuclear redox signaling affected by Cd-Although many toxicity studies have emphasized the critical nature of effects on mitochondria, homeostatic regulation of organ systems, defense against environmental agents, proliferation, differentiation and programmed cell death, occur through integrated activities of molecular signaling and control systems that ultimately converge in cell nuclei. Cd, considered to be a human carcinogen due to its mutagenic and carcinogenic properties, might induce carcinogenesis though mechanisms of interaction with DNA (Valverde et al., 2001). However, the role of $\mathrm{Cd}$ in nuclear events is largely unknown, i.e., studies specifically investigating low-dose effects of $\mathrm{Cd}$ focusing on nuclear redox signaling are very limited. Nuclear redox modules as outlined in Fig 5 could represent important targets that contribute to carcinogenicity of $\mathrm{Cd}$.

Data with $\mathrm{Cd}$ administration at high doses (over $10 \mu \mathrm{M}$ or $1 \mathrm{mg} / \mathrm{kg}$ body weight) showed that Cd induces DNA damage and affects the DNA repair system (Candeias et al., 2010, Nemmiche et al., 2011). Human Jurkat T-cells exposed to Cd (5-50 $\mu \mathrm{M}, 24 \mathrm{~h})$ showed increased death in association with elevated levels of DNA damage, lipid peroxidation and protein carbonyls and decreased activity of superoxide dismutase and GPx (Nemmiche et al., 2011). Cd inhibited base and nucleotide excision/repair pathways by affecting mainly the recognition and excision stages of these processes suggesting that $\mathrm{Cd}$ is a potent DNA repair poison (Candeias et al., 2010). Significant DNA damage by high-dose Cd was also observed in a mouse study using low non-cytotoxic concentrations of Cd ( $\triangle .0 \mu \mathrm{M})$ (Valverde et al., 2001). This study additionally showed that Cd-induced DNA damage resulted from an increased level of oxidative stress such as elevation of lipid peroxidation and free radicals but not due to direct interaction of Cd with DNA. Consistent with this, chronic low Cd (4.4 $\mathrm{mg} / \mathrm{kg}$ ) also induced nuclear DNA damage in rat liver with increased urinary excretion of oxidized lipids (Bagchi et al., 1997). Another earlier study also showed that Cd (5-35 $\mu \mathrm{M})$ induced DNA strand breaks with increased formation of 8-hydroxy-2'-deoxyguanosine in human lymphoblastoid cells (Mikhailova et al., 1997). In the same study, Cd at a higher level $(50 \mu \mathrm{M})$ induced significant increase in activity of nuclear superoxide dismutase and catalase but decrease in GSH level and oxidation of $\mathrm{E}_{\mathrm{h}} \mathrm{GSSG}$ (Mikhailova et al., 1997).

In a recent study (Go et al., 2012), we investigated the role of nuclear-localized $\operatorname{Trx} 1$ in Cdinduced inflammation and cytotoxicity using in vitro and in vivo models. The results showed that submicromolar Cd stimulated nuclear translocation of Trx 1 and p65 of NF- $\kappa B$ in HeLa cells. Elevation of Trx 1 in nuclei in cells in vitro and kidney of transgenic mice containing Trx1 fused to a nuclear localization signal (NLS-Trx1) had increased Cd-stimulated NF- $\kappa B$ activation and cell death. In these experiments, Cd-stimulated Trx1 nuclear translocation and 
NF- $\kappa \mathrm{B}$ activation were inhibited by cytochalasin $\mathrm{D}$, an inhibitor of actin polymerization. The results suggest that actin regulates Trx 1 nuclear translocation and NF- $\kappa B$ activation by $\mathrm{Cd}$. A nuclear-targeted dominant negative form of Trx 1 blocked Cd-stimulated NF- $\kappa \mathrm{B}$ activation and decreased cell death. Addition of zinc, known to antagonize $\mathrm{Cd}$ toxicity by increasing metallothionein, had no effect on Cd-stimulated nuclear translocation of $\operatorname{Trx} 1$ and $\mathrm{NF}-\kappa \mathrm{B}$ activation. The data show that nuclear thiol redox systems are important in $\mathrm{Cd}$ toxicity, and taken together with the above data for mitochondria, show a complex interaction of $\mathrm{Cd}$ with thiol redox systems that can have diverse and important roles in disease and toxicities. Application of developing concepts of redox systems biology could substantially improve understanding of the complex effects of $\mathrm{Cd}$ on these systems.

\section{Summary and Perspectives}

A wealth of experimental data on thiol redox systems has accumulated, providing an essential resource for development of integrated redox systems biology. While details remain unclear, central organizational features have emerged. These features provide a framework for consideration of a bilateral hierarchical structure within multiple subcellular compartments and consisting of opposing reductive redox regulons (e.g. Trx, GSH) and oxidative redox regulons (e.g., $\mathrm{H}_{2} \mathrm{O}_{2}, \mathrm{ROOH}$, quinones, peroxynitrite). With only a small number of secondary redox elements, this structure is sufficient to control the redox state of each of the 214,000 Cys encoded in the mammalian genome. Application of mass spectrometry-based redox proteomics is beginning to further reveal organizational substructures in which Cys in proteins with common biologic functions have similar steadystate level of oxidation. Although early in development, redox systems biology approaches could considerably enhance understanding of complex thiol mechanisms such as oxidative stress in disease, chronic toxicities from low-level environmental exposures and therapeutics for cancer and other diseases.

\section{References}

Adimora NJ, Jones DP, Kemp ML. A model of redox kinetics implicates the thiol proteome in cellular hydrogen peroxide responses. Antioxid Redox Signal. 2010; 13:731-43. [PubMed: 20121341]

Anand P, Stamler JS. Enzymatic mechanisms regulating protein S-nitrosylation: implications in health and disease. Journal of molecular medicine. 2012; 90:233-44. [PubMed: 22361849]

Anathy V, Roberson EC, Guala AS, Godburn KE, Budd RC, Janssen-Heininger YM. Redox-based regulation of apoptosis: S-glutathionylation as a regulatory mechanism to control cell death. Antioxidants \& redox signaling. 2012; 16:496-505. [PubMed: 21929356]

Anderson CL, Iyer SS, Ziegler TR, Jones DP. Control of extracellular cysteine/cystine redox state by HT29 cells is independent of cellular glutathione. Am J Physiol Regul Integr Comp Physiol. 2007

Arita A, Costa M. Epigenetics in metal carcinogenesis: nickel, arsenic, chromium and cadmium. Metallomics : integrated biometal science. 2009; 1:222-8. [PubMed: 20461219]

Arner ES, Holmgren A. Physiological functions of thioredoxin and thioredoxin reductase. European journal of biochemistry / FEBS. 2000; 267:6102-9. [PubMed: 11012661]

Aw TY, Williams MW. Intestinal absorption and lymphatic transport of peroxidized lipids in rats: effect of exogenous GSH. Am J Physiol. 1992; 263:G665-72. [PubMed: 1443140]

Aw TY, Williams MW, Gray L. Absorption and lymphatic transport of peroxidized lipids by rat small intestine in vivo: role of mucosal GSH. Am J Physiol. 1992; 262:G99-106. [PubMed: 1733274] 
Bagchi D, Vuchetich PJ, Bagchi M, Hassoun EA, Tran MX, Tang L, Stohs SJ. Induction of oxidative stress by chronic administration of sodium dichromate [chromium VI] and cadmium chloride [cadmium II] to rats. Free radical biology \& medicine. 1997; 22:471-8. [PubMed: 8981039]

Baker JR, Satarug S, Urbenjapol S, Edwards RJ, Williams DJ, Moore MR, Reilly PE. Associations between human liver and kidney cadmium content and immunochemically detected CYP4A11 apoprotein. Biochemical pharmacology. 2002; 63:693-6. [PubMed: 11992637]

Barabasi AL. Scale-free networks: a decade and beyond. Science. 2009; 325:412-3. [PubMed: 19628854]

Bartosiewicz M, Penn S, Buckpitt A. Applications of gene arrays in environmental toxicology: fingerprints of gene regulation associated with cadmium chloride, benzo(a)pyrene, and trichloroethylene. Environmental health perspectives. 2001; 109:71-4. [PubMed: 11171528]

Bauer R, Demeter I, Hasemann V, Johansen JT. Structural properties of the zinc site in Cu,Znsuperoxide dismutase; perturbed angular correlation of gamma ray spectroscopy on the $\mathrm{Cu}$, $111 \mathrm{Cd}$-superoxide dismutase derivative. Biochemical and biophysical research communications. 1980; 94:1296-302. [PubMed: 6994739]

Belyaeva EA, Korotkov SM. Mechanism of primary Cd2+-induced rat liver mitochondria dysfunction: discrete modes of $\mathrm{Cd} 2+$ action on calcium and thiol-dependent domains. Toxicology and applied pharmacology. 2003; 192:56-68. [PubMed: 14554103]

Bender A, Hajieva P, Moosmann B. Adaptive antioxidant methionine accumulation in respiratory chain complexes explains the use of a deviant genetic code in mitochondria. Proceedings of the National Academy of Sciences of the United States of America. 2008; 105:16496-501. [PubMed: 18946048]

Berg, J.; Tymoczko, J.; Stryer, L. Deoxyribonucleotides Synthesized by the Reduction of Ribonucleotides Through a Radical Mechanism. In: FREEMAN, W., editor. Biochemistry. 5. New York: 2002.

Beyersmann D, Block C, Malviya AN. Effects of cadmium on nuclear protein kinase C. Environmental health perspectives. 1994; 102(Suppl 3):177-80. [PubMed: 7843094]

Beyersmann D, Hechtenberg S. Cadmium, gene regulation, and cellular signalling in mammalian cells. Toxicology and applied pharmacology. 1997; 144:247-61. [PubMed: 9194408]

Blanco RA, Ziegler TR, Carlson BA, Cheng PY, Park Y, Cotsonis GA, Accardi CJ, Jones DP. Diurnal variation in glutathione and cysteine redox states in human plasma. Am J Clin Nutr. 2007; 86:1016-23. [PubMed: 17921379]

Brandes N, Schmitt S, Jakob U. Thiol-based redox switches in eukaryotic proteins. Antioxidants \& redox signaling. 2009; 11:997-1014. [PubMed: 18999917]

Brzoska MM, Moniuszko-Jakoniuk J. The influence of calcium content in diet on cumulation and toxicity of cadmium in the organism. Archives of toxicology. 1998; 72:63-73. [PubMed: 9456077]

Buchko GW, Hess NJ, Kennedy MA. Cadmium mutagenicity and human nucleotide excision repair protein XPA: CD, EXAFS and (1)H/(15)N-NMR spectroscopic studies on the zinc(II)- and cadmium(II)-associated minimal DNA-binding domain (M98-F219). Carcinogenesis. 2000; 21:1051-7. [PubMed: 10783332]

Burk RF. Selenium, an antioxidant nutrient. Nutrition in clinical care : an official publication of Tufts University. 2002; 5:75-9. [PubMed: 12134713]

Cadenas E, Davies KJ. Mitochondrial free radical generation, oxidative stress, and aging. Free Radic Biol Med. 2000; 29:222-30. [PubMed: 11035250]

Cameron I, McNamee PM, Markham A, Morgan RM, Wood M. The effects of cadmium on succinate and NADH-linked substrate oxidations in rat hepatic mitochondria. Journal of applied toxicology : JAT. 1986; 6:325-30. [PubMed: 3772008]

Candeias S, Pons B, Viau M, Caillat S, Sauvaigo S. Direct inhibition of excision/synthesis DNA repair activities by cadmium: analysis on dedicated biochips. Mutation research. 2010; 694:53-9. [PubMed: 20969882]

Cannino G, Ferruggia E, Luparello C, Rinaldi AM. Cadmium and mitochondria. Mitochondrion. 2009; 9:377-84. [PubMed: 19706341] 
Casagrande S, Bonetto V, Fratelli M, Gianazza E, Eberini I, Massignan T, Salmona M, Chang G, Holmgren A, Ghezzi P. Glutathionylation of human thioredoxin: a possible crosstalk between the glutathione and thioredoxin systems. Proc Natl Acad Sci U S A. 2002; 99:9745-9. [PubMed: 12119401]

Cenci S, Sitia R. Managing and exploiting stress in the antibody factory. FEBS Lett. 2007; 581:36527. [PubMed: 17475256]

Cenci S, van Anken E, Sitia R. Proteostenosis and plasma cell pathophysiology. Current opinion in cell biology. 2011; 23:216-22. [PubMed: 21169004]

Chance B. Spectra and reaction kinetics of respiratory pigments of homogenized and intact cells. Nature. 1952; 169:215-21. [PubMed: 14910730]

Chance B. Spectrophotometry of intracellular respiratory pigments. Science. 1954; 120:767-75. [PubMed: 13216168]

Chawla RK, Lewis FW, Kutner MH, Bate DM, Roy RG, Rudman D. Plasma cysteine, cystine, and glutathione in cirrhosis. Gastroenterology. 1984; 87:770-6. [PubMed: 6468868]

Chen J, Goldsbrough PB. Increased Activity of [gamma]-Glutamylcysteine Synthetase in Tomato Cells Selected for Cadmium Tolerance. Plant physiology. 1994; 106:233-239. [PubMed: 12232324]

Chrestensen CA, Starke DW, Mieyal JJ. Acute cadmium exposure inactivates thioltransferase (Glutaredoxin), inhibits intracellular reduction of protein-glutathionyl-mixed disulfides, and initiates apoptosis. The Journal of biological chemistry. 2000; 275:26556-65. [PubMed: 10854441]

Conterato GM, Bulcao RP, Sobieski R, Moro AM, Charao MF, Freitas FA, Almeida FL, Moreira AP, Roehrs M, Tonello R, Batista BL, Grotto D, Barbosa F Jr, Garcia SC, Emanuelli T. Blood thioredoxin reductase activity, oxidative stress and hematological parameters in painters and battery workers: relationship with lead and cadmium levels in blood. Journal of applied toxicology : JAT. 2011

Crane D, Haussinger D, Sies H. Rise of coenzyme A-glutathione mixed disulfide during hydroperoxide metabolism in perfused rat liver. European journal of biochemistry / FEBS. 1982; 127:575-8. [PubMed: 7173198]

Crow JP, Beckman JS, McCord JM. Sensitivity of the essential zinc-thiolate moiety of yeast alcohol dehydrogenase to hypochlorite and peroxynitrite. Biochemistry. 1995; 34:3544-52. [PubMed: 7893650]

Cuypers A, Plusquin M, Remans T, Jozefczak M, Keunen E, Gielen H, Opdenakker K, Nair AR, Munters E, Artois TJ, Nawrot T, Vangronsveld J, Smeets K. Cadmium stress: an oxidative challenge. Biometals : an international journal on the role of metal ions in biology, biochemistry, and medicine. 2010; 23:927-40.

D'Autreaux B, Toledano MB. ROS as signalling molecules: mechanisms that generate specificity in ROS homeostasis. Nat Rev Mol Cell Biol. 2007; 8:813-24. [PubMed: 17848967]

Deckert J. Cadmium toxicity in plants: is there any analogy to its carcinogenic effect in mammalian cells? Biometals : an international journal on the role of metal ions in biology, biochemistry, and medicine. 2005; 18:475-81.

Deneke SM, Fanburg BL. Regulation of cellular glutathione. The American journal of physiology. 1989; 257:L163-73. [PubMed: 2572174]

Dooley CT, Dore TM, Hanson GT, Jackson WC, Remington SJ, Tsien RY. Imaging dynamic redox changes in mammalian cells with green fluorescent protein indicators. The Journal of biological chemistry. 2004; 279:22284-93. [PubMed: 14985369]

Early JL 2nd, Nonavinakere VK, Weaver A. Effect of cadmium and/or selenium on liver mitochondria and rough endoplasmic reticulum in the rat. Toxicology letters. 1992; 62:73-83. [PubMed: 1509509]

El-Sharaky AS, Newairy AA, Badreldeen MM, Eweda SM, Sheweita SA. Protective role of selenium against renal toxicity induced by cadmium in rats. Toxicology. 2007; 235:185-93. [PubMed: 17448585]

Elshorbagy AK, Nurk E, Gjesdal CG, Tell GS, Ueland PM, Nygard O, Tverdal A, Vollset SE, Refsum H. Homocysteine, cysteine, and body composition in the Hordaland Homocysteine Study: does 
cysteine link amino acid and lipid metabolism? The American journal of clinical nutrition. 2008; 88:738-46. [PubMed: 18779291]

Essex DW, Li M. Redox control of platelet aggregation. Biochemistry. 2003; 42:129-36. [PubMed: 12515547]

Forman HJ, Zhang H, Rinna A. Glutathione: overview of its protective roles, measurement, and biosynthesis. Molecular aspects of medicine. 2009; 30:1-12. [PubMed: 18796312]

Frazier, JM. Need for Physiologically Based Toxocokinetic Models in Estimating Target Organ Dosage Following Oral Ingestion of Cadmium. In: RHODA, GMW., editor. Environmental science and pollution control. Marcel Dekker, Inc; 1994.

Funato Y, Miki H. Nucleoredoxin, a novel thioredoxin family member involved in cell growth and differentiation. Antioxidants \& redox signaling. 2007; 9:1035-57. [PubMed: 17567240]

Gadalla MM, Snyder SH. Hydrogen sulfide as a gasotransmitter. Journal of neurochemistry. 2010; 113:14-26. [PubMed: 20067586]

Gallagher CM, Kovach JS, Meliker JR. Urinary cadmium and osteoporosis in U.S. Women >or= 50 years of age: NHANES 1988-1994 and 1999-2004. Environmental health perspectives. 2008; 116:1338-43. [PubMed: 18941575]

Gerhard I, Monga B, Waldbrenner A, Runnebaum B. Heavy metals and fertility. Journal of toxicology and environmental health. Part A. 1998; 54:593-611. [PubMed: 9726782]

Gilbert HF. Molecular and cellular aspects of thiol-disulfide exchange. Adv Enzymol Relat Areas Mol Biol. 1990a; 63:69-172. [PubMed: 2407068]

Gilbert HF. Molecular and cellular aspects of thiol-disulfide exchange. Advances in enzymology and related areas of molecular biology. 1990b; 63:69-172. [PubMed: 2407068]

Giustarini D, Rossi R, Milzani A, Colombo R, Dalle-Donne I. S-glutathionylation: from redox regulation of protein functions to human diseases. Journal of cellular and molecular medicine. 2004; 8:201-12. [PubMed: 15256068]

Gladyshev VN, Hatfield DL. Selenocysteine-containing proteins in mammals. Journal of biomedical science. 1999; 6:151-60. [PubMed: 10343164]

Gleason FK, Holmgren A. Isolation and characterization of thioredoxin from the cyanobacterium, Anabaena sp. The Journal of biological chemistry. 1981; 256:8306-9. [PubMed: 6790538]

Go YM, Duong DM, Peng J, Jones DP. Protein Cysteines Map to Functional Networks According to Steady-state Level of Oxidation. Journal of proteomics \& bioinformatics. 2011; 4:196-209. [PubMed: 22605892]

Go YM, Gipp JJ, Mulcahy RT, Jones DP. H2O2-dependent activation of GCLC-ARE4 reporter occurs by mitogen-activated protein kinase pathways without oxidation of cellular glutathione or thioredoxin-1. J Biol Chem. 2004; 279:5837-45. [PubMed: 14638694]

Go YM, Jones DP. Redox compartmentalization in eukaryotic cells. Biochimica et biophysica acta. 2008; 1780:1273-90. [PubMed: 18267127]

Go YM, Jones DP. Redox clamp model for study of extracellular thiols and disulfides in redox signaling. Methods Enzymol. 2010a; 474:165-79. [PubMed: 20609910]

Go YM, Jones DP. Redox control systems in the nucleus: mechanisms and functions. Antioxid Redox Signal. 2010b; 13:489-509. [PubMed: 20210649]

Go YM, Orr M, Jones DP. Increased nuclear thioredoxin-1 potentiates cadmium-induced cytotoxicity. Toxicological sciences. 2012 In Press.

Go YM, Park H, Koval M, Orr M, Reed M, Liang Y, Smith D, Pohl J, Jones DP. A key role for mitochondria in endothelial signaling by plasma cysteine/cystine redox potential. Free Radic Biol Med. 2010; 48:275-83. [PubMed: 19879942]

Go YM, Pohl J, Jones DP. Quantification of redox conditions in the nucleus. Methods in molecular biology. 2009; 464:303-17. [PubMed: 18951192]

Go YM, Ziegler TR, Johnson JM, Gu L, Hansen JM, Jones DP. Selective protection of nuclear thioredoxin-1 and glutathione redox systems against oxidation during glucose and glutamine deficiency in human colonic epithelial cells. Free Radic Biol Med. 2007; 42:363-70. [PubMed: 17210449] 
Gonzalez Porque P, Baldesten A, Reichard P. The involvement of the thioredoxin system in the reduction of methionine sulfoxide and sulfate. The Journal of biological chemistry. 1970; 245:2371-4. [PubMed: 4392601]

Gravina SA, Mieyal JJ. Thioltransferase is a specific glutathionyl mixed disulfide oxidoreductase. Biochemistry. 1993; 32:3368-76. [PubMed: 8461300]

Gutscher M, Pauleau AL, Marty L, Brach T, Wabnitz GH, Samstag Y, Meyer AJ, Dick TP. Real-time imaging of the intracellular glutathione redox potential. Nature methods. 2008; 5:553-9. [PubMed: 18469822]

Haendeler J, Hoffmann J, Tischler V, Berk BC, Zeiher AM, Dimmeler S. Redox regulatory and antiapoptotic functions of thioredoxin depend on S-nitrosylation at cysteine 69. Nature cell biology. 2002; 4:743-9.

Halvey PJ, Watson WH, Hansen JM, Go YM, Samali A, Jones DP. Compartmental oxidation of thioldisulphide redox couples during epidermal growth factor signalling. Biochem J. 2005; 386:215-9. [PubMed: 15647005]

Hansen JM, Watson WH, Jones DP. Compartmentation of Nrf-2 redox control: regulation of cytoplasmic activation by glutathione and DNA binding by thioredoxin-1. Toxicol Sci. 2004; 82:308-17. [PubMed: 15282410]

Hansen JM, Zhang H, Jones DP. Differential oxidation of thioredoxin-1, thioredoxin-2, and glutathione by metal ions. Free radical biology \& medicine. 2006; 40:138-45. [PubMed: 16337887]

Hanson GT, Aggeler R, Oglesbee D, Cannon M, Capaldi RA, Tsien RY, Remington SJ. Investigating mitochondrial redox potential with redox-sensitive green fluorescent protein indicators. The Journal of biological chemistry. 2004; 279:13044-53. [PubMed: 14722062]

Hashemy SI, Holmgren A. Regulation of the catalytic activity and structure of human thioredoxin 1 via oxidation and S-nitrosylation of cysteine residues. The Journal of biological chemistry. 2008; 283:21890-8. [PubMed: 18544525]

Holmgren A. Glutathione-dependent synthesis of deoxyribonucleotides. Characterization of the enzymatic mechanism of Escherichia coli glutaredoxin. The Journal of biological chemistry. 1979; 254:3672-8. [PubMed: 34620]

Holmgren A. Thioredoxin. Annual review of biochemistry. 1985; 54:237-71.

Holmgren A. Thioredoxin and glutaredoxin systems. J Biol Chem. 1989; 264:13963-6. [PubMed: 2668278]

Horiguchi H, Oguma E, Kayama F. Cadmium induces anemia through interdependent progress of hemolysis, body iron accumulation, and insufficient erythropoietin production in rats.

Toxicological sciences : an official journal of the Society of Toxicology. 2011; 122:198-210. [PubMed: 21540277]

Hsiao CJ, Stapleton SR. Early sensing and gene expression profiling under a low dose of cadmium exposure. Biochimie. 2009; 91:329-43. [PubMed: 19010381]

Huang YH, Shih CM, Huang CJ, Lin CM, Chou CM, Tsai ML, Liu TP, Chiu JF, Chen CT. Effects of cadmium on structure and enzymatic activity of $\mathrm{Cu}, \mathrm{Zn}-\mathrm{SOD}$ and oxidative status in neural cells. Journal of cellular biochemistry. 2006; 98:577-89. [PubMed: 16440303]

Hwang C, Sinskey AJ, Lodish HF. Oxidized redox state of glutathione in the endoplasmic reticulum. Science. 1992; 257:1496-502. [PubMed: 1523409]

Ishima Y, Sawa T, Kragh-Hansen U, Miyamoto Y, Matsushita S, Akaike T, Otagiri M. S-Nitrosylation of human variant albumin Liprizzi (R410C) confers potent antibacterial and cytoprotective properties. The Journal of pharmacology and experimental therapeutics. 2007; 320:969-77. [PubMed: 17135341]

Jeong W, Jung Y, Kim H, Park SJ, Rhee SG. Thioredoxin-related protein 14, a new member of the thioredoxin family with disulfide reductase activity: implication in the redox regulation of TNFalpha signaling. Free radical biology \& medicine. 2009; 47:1294-303. [PubMed: 19628032]

Jiang LJ, Maret W, Vallee BL. The glutathione redox couple modulates zinc transfer from metallothionein to zinc-depleted sorbitol dehydrogenase. Proceedings of the National Academy of Sciences of the United States of America. 1998; 95:3483-8. [PubMed: 9520392] 
Jones DP. Disruption of mitochondrial redox circuitry in oxidative stress. Chem Biol Interact. 2006; 163:38-53. [PubMed: 16970935]

Jones DP. Radical-free biology of oxidative stress. Am J Physiol Cell Physiol. 2008; 295:C849-68. [PubMed: 18684987]

Jones DP. Redox sensing: orthogonal control in cell cycle and apoptosis signalling. Journal of internal medicine. 2010; 268:432-48. [PubMed: 20964735]

Jones DP, Aw TY, Sillau AH. Defining the resistance to oxygen transfer in tissue hypoxia. Experientia. 1990; 46:1180-5. [PubMed: 2253719]

Jones DP, Carlson JL, Mody VC, Cai J, Lynn MJ, Sternberg P. Redox state of glutathione in human plasma. Free Radic Biol Med. 2000; 28:625-35. [PubMed: 10719244]

Jones DP, Eklow L, Thor H, Orrenius S. Metabolism of hydrogen peroxide in isolated hepatocytes: relative contributions of catalase and glutathione peroxidase in decomposition of endogenously generated H2O2. Arch Biochem Biophys. 1981; 210:505-16. [PubMed: 7305340]

Jones DP, Go YM. Redox compartmentalization and cellular stress. Diabetes, obesity \& metabolism. 2010; 12(Suppl 2):116-25.

Jones DP, Go YM, Anderson CL, Ziegler TR, Kinkade JM Jr, Kirlin WG. Cysteine/cystine couple is a newly recognized node in the circuitry for biologic redox signaling and control. Faseb J. 2004; 18:1246-8. [PubMed: 15180957]

Jones DP, Liang Y. Measuring the poise of thiol/disulfide couples in vivo. Free Radic Biol Med. 2009; 47:1329-38. [PubMed: 19715755]

Jones DP, Mody VC Jr, Carlson JL, Lynn MJ, Sternberg P Jr. Redox analysis of human plasma allows separation of pro-oxidant events of aging from decline in antioxidant defenses. Free Radic Biol Med. 2002; 33:1290-300. [PubMed: 12398937]

Kadokura H, Beckwith J. Mechanisms of oxidative protein folding in the bacterial cell envelope. Antioxidants \& redox signaling. 2010; 13:1231-46. [PubMed: 20367276]

Kamga CK, Zhang SX, Wang Y. Dicarboxylate carrier-mediated glutathione transport is essential for reactive oxygen species homeostasis and normal respiration in rat brain mitochondria. American journal of physiology. Cell physiology. 2010; 299:C497-505. [PubMed: 20538765]

Karsai M, Kaski K, Barabasi AL, Kertesz J. Universal features of correlated bursty behaviour. Scientific reports. 2012; 2:397. [PubMed: 22563526]

Kasaikina MV, Hatfield DL, Gladyshev VN. Understanding selenoprotein function and regulation through the use of rodent models. Biochimica et biophysica acta. 2012; 1823:1633-42. [PubMed: 22440326]

Kazantzis G. Cadmium, osteoporosis and calcium metabolism. Biometals : an international journal on the role of metal ions in biology, biochemistry, and medicine. 2004; 17:493-8.

Kemp M, Go YM, Jones DP. Nonequilibrium thermodynamics of thiol/disulfide redox systems: a perspective on redox systems biology. Free Radic Biol Med. 2008; 44:921-37. [PubMed: 18155672]

Kippner LE, Finn NA, Shukla S, Kemp ML. Systemic remodeling of the redox regulatory network due to RNAi perturbations of glutaredoxin 1, thioredoxin 1, and glucose-6-phosphate dehydrogenase. BMC systems biology. 2011; 5:164. [PubMed: 21995976]

Kirlin WG, Cai J, Thompson SA, Diaz D, Kavanagh TJ, Jones DP. Glutathione redox potential in response to differentiation and enzyme inducers. Free radical biology \& medicine. 1999; 27:1208-18. [PubMed: 10641713]

Klaassen CD, Liu J, Choudhuri S. Metallothionein: an intracellular protein to protect against cadmium toxicity. Annual review of pharmacology and toxicology. 1999; 39:267-94.

Lampe BJ, Park SK, Robins T, Mukherjee B, Litonjua AA, Amarasiriwardena C, Weisskopf M, Sparrow D, Hu H. Association between 24-hour urinary cadmium and pulmonary function among community-exposed men: the VA Normative Aging Study. Environmental health perspectives. 2008; 116:1226-30. [PubMed: 18795167]

Lash LH. Renal glutathione transport: Identification of carriers, physiological functions, and controversies. BioFactors. 2009; 35:500-8. [PubMed: 19904718]

Laudanski T, Sipowicz M, Modzelewski P, Bolinski J, Szamatowicz J, Razniewska G, Akerlund M. Influence of high lead and cadmium soil content on human reproductive outcome. International 
journal of gynaecology and obstetrics: the official organ of the International Federation of Gynaecology and Obstetrics. 1991; 36:309-15.

Le Moan N, Clement G, Le Maout S, Tacnet F, Toledano MB. The Saccharomyces cerevisiae proteome of oxidized protein thiols: contrasted functions for the thioredoxin and glutathione pathways. The Journal of biological chemistry. 2006; 281:10420-30. [PubMed: 16418165]

Leichert LI, Gehrke F, Gudiseva HV, Blackwell T, Ilbert M, Walker AK, Strahler JR, Andrews PC, Jakob U. Quantifying changes in the thiol redox proteome upon oxidative stress in vivo. Proceedings of the National Academy of Sciences of the United States of America. 2008; 105:8197-202. [PubMed: 18287020]

Leonard SE, Reddie KG, Carroll KS. Mining the thiol proteome for sulfenic acid modifications reveals new targets for oxidation in cells. ACS Chem Biol. 2009; 4:783-99. [PubMed: 19645509]

Li L, Rose P, Moore PK. Hydrogen sulfide and cell signaling. Annual review of pharmacology and toxicology. 2011; 51:169-87.

Lillig CH, Berndt C, Vergnolle O, Lonn ME, Hudemann C, Bill E, Holmgren A. Characterization of human glutaredoxin 2 as iron-sulfur protein: a possible role as redox sensor. Proceedings of the National Academy of Sciences of the United States of America. 2005; 102:8168-73. [PubMed: 15917333]

Low FM, Hampton MB, Peskin AV, Winterbourn CC. Peroxiredoxin 2 functions as a noncatalytic scavenger of low-level hydrogen peroxide in the erythrocyte. Blood. 2007; 109:2611-7. [PubMed: 17105810]

Lu SC. Regulation of hepatic glutathione synthesis: current concepts and controversies. FASEB journal : official publication of the Federation of American Societies for Experimental Biology. 1999; 13:1169-83. [PubMed: 10385608]

Lyles MM, Gilbert HF. Catalysis of the oxidative folding of ribonuclease A by protein disulfide isomerase: dependence of the rate on the composition of the redox buffer. Biochemistry. 1991; 30:613-9. [PubMed: 1988050]

Mallis RJ, Buss JE, Thomas JA. Oxidative modification of H-ras: S-thiolation and S-nitrosylation of reactive cysteines. The Biochemical journal. 2001; 355:145-53. [PubMed: 11256959]

Mandal PK, Seiler A, Perisic T, Kolle P, Banjac Canak A, Forster H, Weiss N, Kremmer E, Lieberman MW, Bannai S, Kuhlencordt P, Sato H, Bornkamm GW, Conrad M. System x(c)- and thioredoxin reductase 1 cooperatively rescue glutathione deficiency. The Journal of biological chemistry. 2010; 285:22244-53. [PubMed: 20463017]

Mannervik B, Axelsson K, Sundewall AC, Holmgren A. Relative contributions of thioltransferase-and thioredoxin-dependent systems in reduction of low-molecular-mass and protein disulphides. Biochem J. 1983; 213:519-23. [PubMed: 6351844]

Mannery YO, Ziegler TR, Hao L, Shyntum Y, Jones DP. Characterization of apical and basal thioldisulfide redox regulation in human colonic epithelial cells. American journal of physiology. Gastrointestinal and liver physiology. 2010; 299:G523-30. [PubMed: 20466942]

Mansoor MA, Svardal AM, Schneede J, Ueland PM. Dynamic relation between reduced, oxidized, and protein-bound homocysteine and other thiol components in plasma during methionine loading in healthy men. Clinical chemistry. 1992; 38:1316-21. [PubMed: 1623597]

Maret W, Vallee BL. Thiolate ligands in metallothionein confer redox activity on zinc clusters. Proceedings of the National Academy of Sciences of the United States of America. 1998; 95:3478-82. [PubMed: 9520391]

Markovic J, Mora NJ, Broseta AM, Gimeno A, de-la-Concepcion N, Vina J, Pallardo FV. The depletion of nuclear glutathione impairs cell proliferation in 3t3 fibroblasts. PLoS One. 2009; 4:e6413. [PubMed: 19641610]

Martinez-Ruiz A, Lamas S. S-nitrosylation: a potential new paradigm in signal transduction. Cardiovascular research. 2004; 62:43-52. [PubMed: 15023551]

McCall KA, Huang C, Fierke CA. Function and mechanism of zinc metalloenzymes. The Journal of nutrition. 2000; 130:1437S-46S. [PubMed: 10801957]

Mendoza-Cozatl D, Loza-Tavera H, Hernandez-Navarro A, Moreno-Sanchez R. Sulfur assimilation and glutathione metabolism under cadmium stress in yeast, protists and plants. FEMS microbiology reviews. 2005; 29:653-71. [PubMed: 16102596] 
Mesonero JE, Rodriguez-Yoldi MC, Rodriguez-Yoldi MJ. Calcium-cadmium interaction on Lthreonine intestinal transport. Reproduction, nutrition, development. 1995; 35:319-28.

Mesonero JE, Yoldi MC, Yoldi MJ. Calcium-cadmium interaction on sugar absorption across the rabbit jejunum. Biological trace element research. 1996; 51:149-59. [PubMed: 8907018]

Mieyal JJ, Chock PB. Posttranslational modification of cysteine in redox signaling and oxidative stress: focus on s-glutathionylation. Antioxidants \& redox signaling. 2012; 16:471-5. [PubMed: 22136616]

Mikhailova MV, Littlefield NA, Hass BS, Poirier LA, Chou MW. Cadmium-induced 8hydroxydeoxyguanosine formation, DNA strand breaks and antioxidant enzyme activities in lymphoblastoid cells. Cancer letters. 1997; 115:141-8. [PubMed: 9149117]

Miller LT, Watson WH, Kirlin WG, Ziegler TR, Jones DP. Oxidation of the glutathione/glutathione disulfide redox state is induced by cysteine deficiency in human colon carcinoma HT29 cells. J Nutr. 2002; 132:2303-6. [PubMed: 12163679]

Miseta A, Csutora P. Relationship between the occurrence of cysteine in proteins and the complexity of organisms. Molecular biology and evolution. 2000; 17:1232-9. [PubMed: 10908643]

Misiti F, Martorana GE, Nocca G, Di Stasio E, Giardina B, Clementi ME. Methionine 35 oxidation reduces toxic and pro-apoptotic effects of the amyloid beta-protein fragment (31-35) on isolated brain mitochondria. Neuroscience. 2004; 126:297-303. [PubMed: 15207347]

Moosmann B. Respiratory chain cysteine and methionine usage indicate a causal role for thiyl radicals in aging. Experimental gerontology. 2011; 46:164-9. [PubMed: 20850516]

Morgan B, Ezerina D, Amoako TN, Riemer J, Seedorf M, Dick TP. Multiple glutathione disulfide removal pathways mediate cytosolic redox homeostasis. Nature chemical biology. 2012

Moriarty-Craige SE, Jones DP. Extracellular thiols and thiol/disulfide redox in metabolism. Annu Rev Nutr. 2004; 24:481-509. [PubMed: 15189129]

Moss M, Guidot DM, Wong-Lambertina M, Ten Hoor T, Perez RL, Brown LA. The effects of chronic alcohol abuse on pulmonary glutathione homeostasis. American journal of respiratory and critical care medicine. 2000; 161:414-9. [PubMed: 10673179]

Murphy MP. Mitochondrial thiols in antioxidant protection and redox signaling: distinct roles for glutathionylation and other thiol modifications. Antioxidants \& redox signaling. 2012; 16:47695. [PubMed: 21954972]

Mustafa AK, Gadalla MM, Sen N, Kim S, Mu W, Gazi SK, Barrow RK, Yang G, Wang R, Snyder SH. H2S signals through protein S-sulfhydration. Science signaling. 2009; 2:ra72. [PubMed: 19903941]

Nakamura T, Lipton SA. S-nitrosylation of critical protein thiols mediates protein misfolding and mitochondrial dysfunction in neurodegenerative diseases. Antioxidants \& redox signaling. 2011; 14:1479-92. [PubMed: 20812868]

Nemmiche S, Chabane-Sari D, Kadri M, Guiraud P. Cadmium chloride-induced oxidative stress and DNA damage in the human Jurkat $\mathrm{T}$ cell line is not linked to intracellular trace elements depletion. Toxicology in vitro : an international journal published in association with BIBRA. 2011; 25:191-8. [PubMed: 21040778]

Newairy AA, El-Sharaky AS, Badreldeen MM, Eweda SM, Sheweita SA. The hepatoprotective effects of selenium against cadmium toxicity in rats. Toxicology. 2007; 242:23-30. [PubMed: 17949884]

Nigam D, Shukla GS, Agarwal AK. Glutathione depletion and oxidative damage in mitochondria following exposure to cadmium in rat liver and kidney. Toxicology letters. 1999; 106:151-7. [PubMed: 10403659]

Nishimoto M, Sakaue M, Hara S. Short-interfering RNA-mediated silencing of thioredoxin reductase 1 alters the sensitivity of HeLa cells toward cadmium. Biological \& pharmaceutical bulletin. 2006; 29:543-6. [PubMed: 16508163]

Nkabyo YS, Ziegler TR, Gu LH, Watson WH, Jones DP. Glutathione and thioredoxin redox during differentiation in human colon epithelial (Caco-2) cells. Am J Physiol Gastrointest Liver Physiol. 2002; 283:G1352-9. [PubMed: 12433666] 
Noonan CW, Sarasua SM, Campagna D, Kathman SJ, Lybarger JA, Mueller PW. Effects of exposure to low levels of environmental cadmium on renal biomarkers. Environmental health perspectives. 2002; 110:151-5. [PubMed: 11836143]

Ochi T, Takahashi K, Ohsawa M. Indirect evidence for the induction of a prooxidant state by cadmium chloride in cultured mammalian cells and a possible mechanism for the induction. Mutation research. 1987; 180:257-66. [PubMed: 3657823]

Ookhtens M, Kaplowitz N. Role of the liver in interorgan homeostasis of glutathione and cyst(e)ine. Seminars in liver disease. 1998; 18:313-29. [PubMed: 9875551]

Permina EA, Medvedeva YA, Baeck PM, Hegde SR, Mande SC, Makeev VJ. Identification of selfconsistent modulons from bacterial microarray expression data with the help of structured regulon gene sets. Journal of biomolecular structure \& dynamics. 2012

Peters JL, Perlstein TS, Perry MJ, McNeely E, Weuve J. Cadmium exposure in association with history of stroke and heart failure. Environmental research. 2010; 110:199-206. [PubMed: 20060521]

Reed, DJ.; Brodie, AE.; Meredith, MJ. Cellular heterogeneity in the status and functions of cysteine and glutathione. New York: Raven Press; 1983.

Refsum H, Ueland PM, Nygard O, Vollset SE. Homocysteine and cardiovascular disease. Annual review of medicine. 1998; 49:31-62.

Reynaert NL, Ckless K, Guala AS, Wouters EF, van der Vliet A, Janssen-Heininger YM. In situ detection of S-glutathionylated proteins following glutaredoxin-1 catalyzed cysteine derivatization. Biochimica et biophysica acta. 2006; 1760:380-7. [PubMed: 16515838]

Roede JR, Go YM, Jones DP. Redox equivalents and mitochondrial bioenergetics. Methods in molecular biology. 2012; 810:249-80. [PubMed: 22057573]

Sagher D, Brunell D, Hejtmancik JF, Kantorow M, Brot N, Weissbach H. Thionein can serve as a reducing agent for the methionine sulfoxide reductases. Proc Natl Acad Sci U S A. 2006; 103:8656-61. [PubMed: 16735467]

Sakurai A, Nishimoto M, Himeno S, Imura N, Tsujimoto M, Kunimoto M, Hara S. Transcriptional regulation of thioredoxin reductase 1 expression by cadmium in vascular endothelial cells: role of NF-E2-related factor-2. Journal of cellular physiology. 2005; 203:529-37. [PubMed: 15521073]

Sali A, Glaeser R, Earnest T, Baumeister W. From words to literature in structural proteomics. Nature. 2003; 422:216-25. [PubMed: 12634795]

Sanz A, Caro P, Ayala V, Portero-Otin M, Pamplona R, Barja G. Methionine restriction decreases mitochondrial oxygen radical generation and leak as well as oxidative damage to mitochondrial DNA and proteins. FASEB journal : official publication of the Federation of American Societies for Experimental Biology. 2006; 20:1064-73. [PubMed: 16770005]

Satarug S, Garrett SH, Sens MA, Sens DA. Cadmium, environmental exposure, and health outcomes. Ciencia \& saude coletiva. 2011; 16:2587-602. [PubMed: 21655733]

Sato N, Kamada T, Suematsu T, Shichiri M, Hayashi N, Matsumura T, Kishida Y, Abe H, Furuyama F, Ishibashi F, Hagihara B. Cadmium toxicity and liver mitochondria. I. Different effects of cadmium administered in vivo to adult, young, and ethionine-fed rats. Journal of biochemistry. 1978; 84:117-25. [PubMed: 690095]

Schafer FQ, Buettner GR. Redox environment of the cell as viewed through the redox state of the glutathione disulfide/glutathione couple. Free radical biology \& medicine. 2001; 30:1191-212. [PubMed: 11368918]

Schutzendubel A, Schwanz P, Teichmann T, Gross K, Langenfeld-Heyser R, Godbold DL, Polle A. Cadmium-induced changes in antioxidative systems, hydrogen peroxide content, and differentiation in Scots pine roots. Plant physiology. 2001; 127:887-98. [PubMed: 11706171]

Sethuraman M, McComb ME, Huang H, Huang S, Heibeck T, Costello CE, Cohen RA. Isotope-coded affinity tag (ICAT) approach to redox proteomics: identification and quantitation of oxidantsensitive cysteine thiols in complex protein mixtures. J Proteome Res. 2004; 3:1228-33. [PubMed: 15595732]

Shukla GS, Shukla A, Potts RJ, Osier M, Hart BA, Chiu JF. Cadmium-mediated oxidative stress in alveolar epithelial cells induces the expression of gamma-glutamylcysteine synthetase catalytic 
subunit and glutathione S-transferase alpha and pi isoforms: potential role of activator protein-1. Cell biology and toxicology. 2000; 16:347-62. [PubMed: 11254161]

Sies H, Summer KH. Hydroperoxide-metabolizing systems in rat liver. Eur J Biochem. 1975; 57:50312. [PubMed: 1175655]

Singhal RK, Anderson ME, Meister A. Glutathione, a first line of defense against cadmium toxicity. FASEB journal : official publication of the Federation of American Societies for Experimental Biology. 1987; 1:220-3. [PubMed: 2887478]

Site, USEPATTNATW. Cadmium Compounds [Online]. U.S. Environmental Protection Agency; 2000. Available: http://www.epa.gov/ttn/atw/hlthef/cadmium.html

Smiri M, Chaoui A, Rouhier N, Gelhaye E, Jacquot JP, El Ferjani E. Cadmium affects the glutathione/ glutaredoxin system in germinating pea seeds. Biological trace element research. 2011; 142:93105. [PubMed: 20552295]

Stadtman ER, Van Remmen H, Richardson A, Wehr NB, Levine RL. Methionine oxidation and aging. Biochim Biophys Acta. 2005; 1703:135-40. [PubMed: 15680221]

Tang W, Shaikh ZA. Renal cortical mitochondrial dysfunction upon cadmium metallothionein administration to Sprague-Dawley rats. Journal of toxicology and environmental health. Part A. 2001; 63:221-35. [PubMed: 11405417]

Taniguchi M, Nagao K, Inoue K, Imaizumi K. Cholesterol lowering effect of sulfur-containing amino acids added to a soybean protein diet in rats. Journal of nutritional science and vitaminology. 2008; 54:448-53. [PubMed: 19155582]

Thevenod F, Friedmann JM, Katsen AD, Hauser IA. Up-regulation of multidrug resistance Pglycoprotein via nuclear factor-kappaB activation protects kidney proximal tubule cells from cadmium- and reactive oxygen species-induced apoptosis. The Journal of biological chemistry. 2000; 275:1887-96. [PubMed: 10636889]

Thijssen S, Maringwa J, Faes C, Lambrichts I, Van Kerkhove E. Chronic exposure of mice to environmentally relevant, low doses of cadmium leads to early renal damage, not predicted by blood or urine cadmium levels. Toxicology. 2007; 229:145-56. [PubMed: 17113697]

Tonks NK. Redox redux: revisiting PTPs and the control of cell signaling. Cell. 2005; 121:667-70. [PubMed: 15935753]

Truong TH, Garcia FJ, Seo YH, Carroll KS. Isotope-coded chemical reporter and acid-cleavable affinity reagents for monitoring protein sulfenic acids. Bioorganic \& medicinal chemistry letters. 2011; 21:5015-20. [PubMed: 21601453]

Valverde M, Trejo C, Rojas E. Is the capacity of lead acetate and cadmium chloride to induce genotoxic damage due to direct DNA-metal interaction? Mutagenesis. 2001; 16:265-70. [PubMed: 11320153]

Vido K, Spector D, Lagniel G, Lopez S, Toledano MB, Labarre J. A proteome analysis of the cadmium response in Saccharomyces cerevisiae. The Journal of biological chemistry. 2001; 276:8469-74. [PubMed: 11078740]

Waalkes MP. Cadmium carcinogenesis. Mutation research. 2003; 533:107-20. [PubMed: 14643415]

Waisberg M, Joseph P, Hale B, Beyersmann D. Molecular and cellular mechanisms of cadmium carcinogenesis. Toxicology. 2003; 192:95-117. [PubMed: 14580780]

Wang L, Li J, Liu Z. Effects of lead and/or cadmium on the oxidative damage of rat kidney cortex mitochondria. Biological trace element research. 2010; 137:69-78. [PubMed: 19902158]

Watson WH, Chen Y, Jones DP. Redox state of glutathione and thioredoxin in differentiation and apoptosis. Biofactors. 2003a; 17:307-14. [PubMed: 12897452]

Watson WH, Heilman JM, Hughes LL, Spielberger JC. Thioredoxin reductase-1 knock down does not result in thioredoxin-1 oxidation. Biochemical and biophysical research communications. 2008; 368:832-6. [PubMed: 18267104]

Watson WH, Pohl J, Montfort WR, Stuchlik O, Reed MS, Powis G, Jones DP. Redox potential of human thioredoxin 1 and identification of a second dithiol/disulfide motif. J Biol Chem. 2003b; 278:33408-15. [PubMed: 12816947]

Winterbourn CC, Metodiewa D. The reaction of superoxide with reduced glutathione. Arch Biochem Biophys. 1994; 314:284-90. [PubMed: 7979367] 
Xanthoudakis S, Curran T. Identification and characterization of Ref-1, a nuclear protein that facilitates AP-1 DNA-binding activity. The EMBO journal. 1992; 11:653-65. [PubMed: 1537340]

Yang MS, Yu LC, Gupta RC. Analysis of changes in energy and redox states in HepG2 hepatoma and C6 glioma cells upon exposure to cadmium. Toxicology. 2004; 201:105-13. [PubMed: 15297025]

Yeh MY, Burnham EL, Moss M, Brown LA. Chronic alcoholism alters systemic and pulmonary glutathione redox status. American journal of respiratory and critical care medicine. 2007; 176:270-6. [PubMed: 17507544]

Yuan L, Kaplowitz N. Glutathione in liver diseases and hepatotoxicity. Molecular aspects of medicine. 2009; 30:29-41. [PubMed: 18786561]

Zeneli L, Daci N, Paçarizi H, Daci-Ajvazi M. Interaction between Cadmium and Calcium in Human Blood at the Smokers. American Journal of Pharmacology and Toxicology. 2010; 5:48-51.

Zhang H, Go YM, Jones DP. Mitochondrial thioredoxin-2/peroxiredoxin-3 system functions in parallel with mitochondrial GSH system in protection against oxidative stress. Arch Biochem Biophys. 2007; 465:119-26. [PubMed: 17548047]

Zhong Q, Putt DA, Xu F, Lash LH. Hepatic mitochondrial transport of glutathione: studies in isolated rat liver mitochondria and H4IIE rat hepatoma cells. Archives of biochemistry and biophysics. 2008; 474:119-27. [PubMed: 18374655]

Ziegler DM. Role of reversible oxidation-reduction of enzyme thiols-disulfides in metabolic regulation. Annual review of biochemistry. 1985; 54:305-29. 


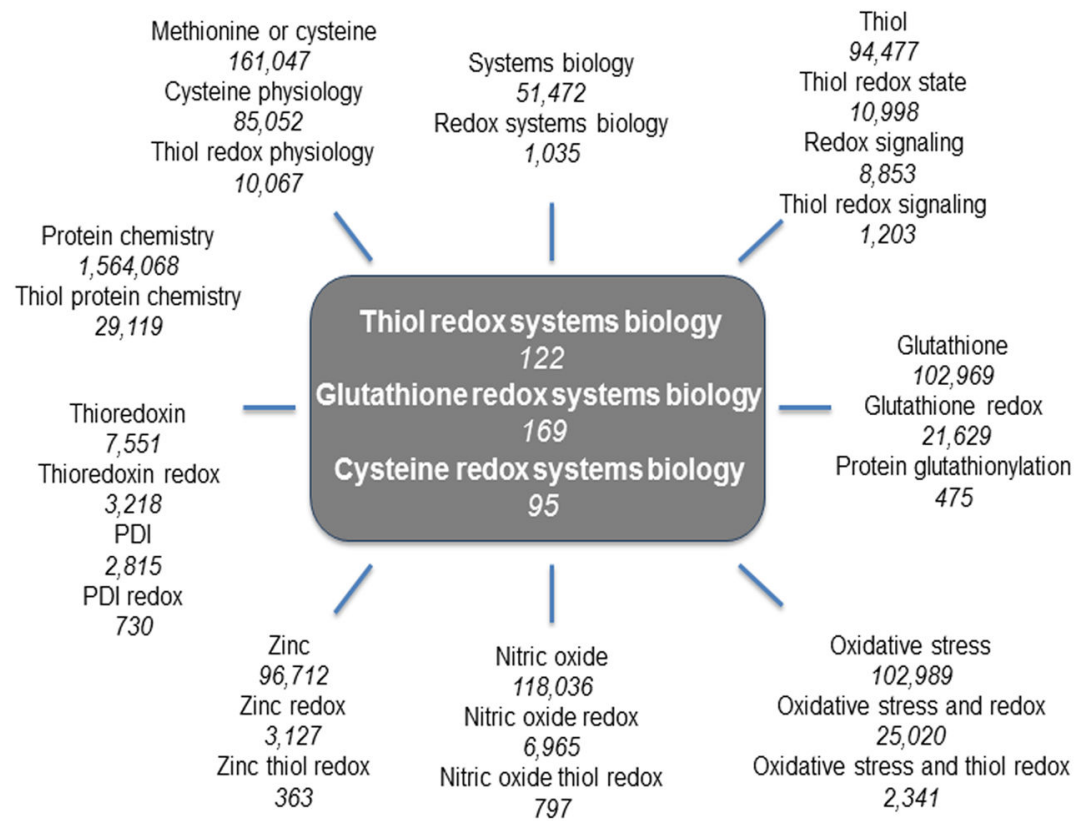

Figure 1.

Genealogy of thiol redox systems biology. Thousands of scientific studies have examined thiol systems in detail, yet integrated knowledge of the complex thiol interactions is only beginning to emerge. Systems biology provides approaches and tools to address this challenging problem. Mass spectrometry-based redox proteomics methods, in particular, provide the ability to simultaneously study redox effects on specific cysteine residues in hundreds of proteins. A search of "redox proteomics" resulted in 995 papers, suggesting a growing influence of this approach. Improved analytic throughput with such methods is expected to support rapid progress in thiol redox systems biology development. 
A

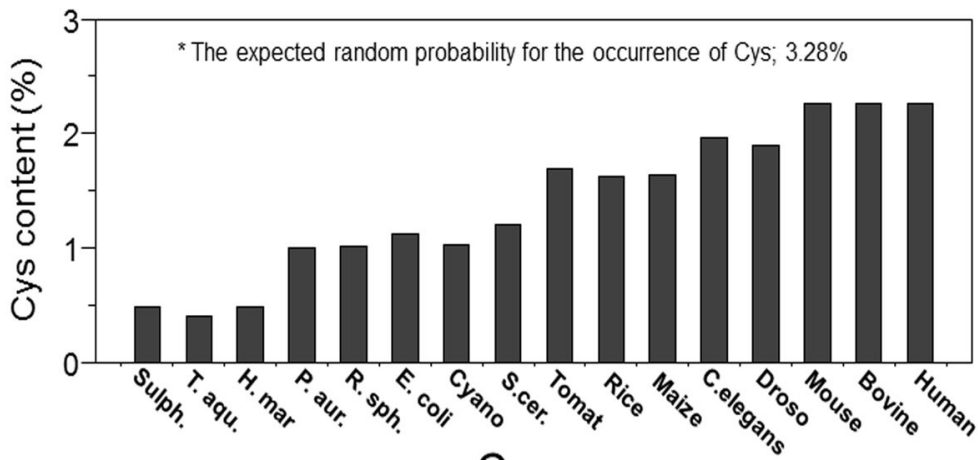

B

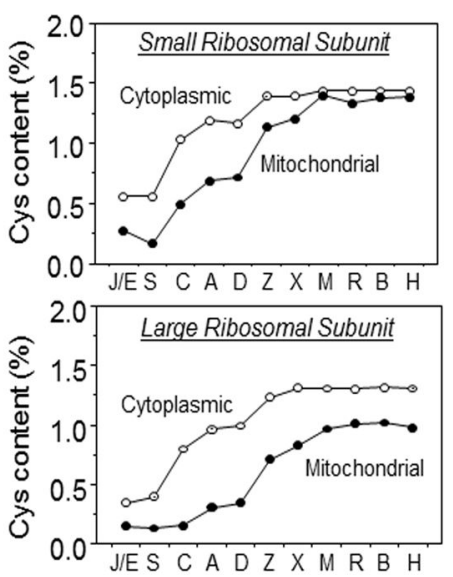

C

Figure 2.

The cysteine proteome co-evolved with structural and functional complexity of higher organisms. A, Modified figure from Miseta and Csutora's study (Fig1 of (Miseta and Csutora, 2000)) The occurrences of the 20 coded amino acids were counted in representative samples of humans, bovines, mice, fruit flies, C. elegans, maize, rice, tomatoes, yeast, Cyanobacteria, E. coli, R. sphaeroides, P. aeruginosa,H. marismortui, T. aquaticus, and Sulpho-archea. The total of all 20 coded amino acids was considered $100 \%$. B, The percentage of conserved/evolved Cys content in cytoplasmic and mitochondrial ribosomal proteins for small subunit (top) and large subunit (bottom) are increased with complexity of the organism, supporting Miseta and Csutora's finding. Abbreviations for species' names; J, Methanococcus jannaschii (cytoplasmic); E, Escherichia coli (mitochondrial); S, Saccharomyces cerevisiae; C, Caenorhabditis elegans; A, Anopheles gambiae; D, Drosophila melanogaster; Z, Danio rerio; X, Xenopus laevis; M, Mus musculus; R, Rattus norvegicus; B, Bos taurus; H, Homo sapiens. C, Modified figure from Go et al. (Fig 8 of (Go et al., 2011)). Evolutionary conservation among vertebrates of mitochondrial peptidyl Cys are associated with functional networks. The UniProt database was searched for protein amino acid sequences of 10 vertebrate species for the peptidyl Cys associated with functional pathways in Fig. 7 of the study by Go et al. (Go et al., 2011). The species included human (Homo sapiens), Sumatran orangutan (Pongo abelii), bovine (Bos taurus), mouse (Mus musculus), rat (Rattus norvegicus), chicken (Gallus gallus), African clawed frog (Xenopus laevis), Western clawed frog (Xenopus tropicalis), zebrafsh (Danio rerio) and Atlantic salmon (Salmo salar). The percentage of identity relative to humans was calculated 
for each of the Cys (filled circles), and the percentage of amino acid identity relative to humans was obtained from a BLAST search in Uniprot (filled triangles), showing that Cys are much more highly conserved. 


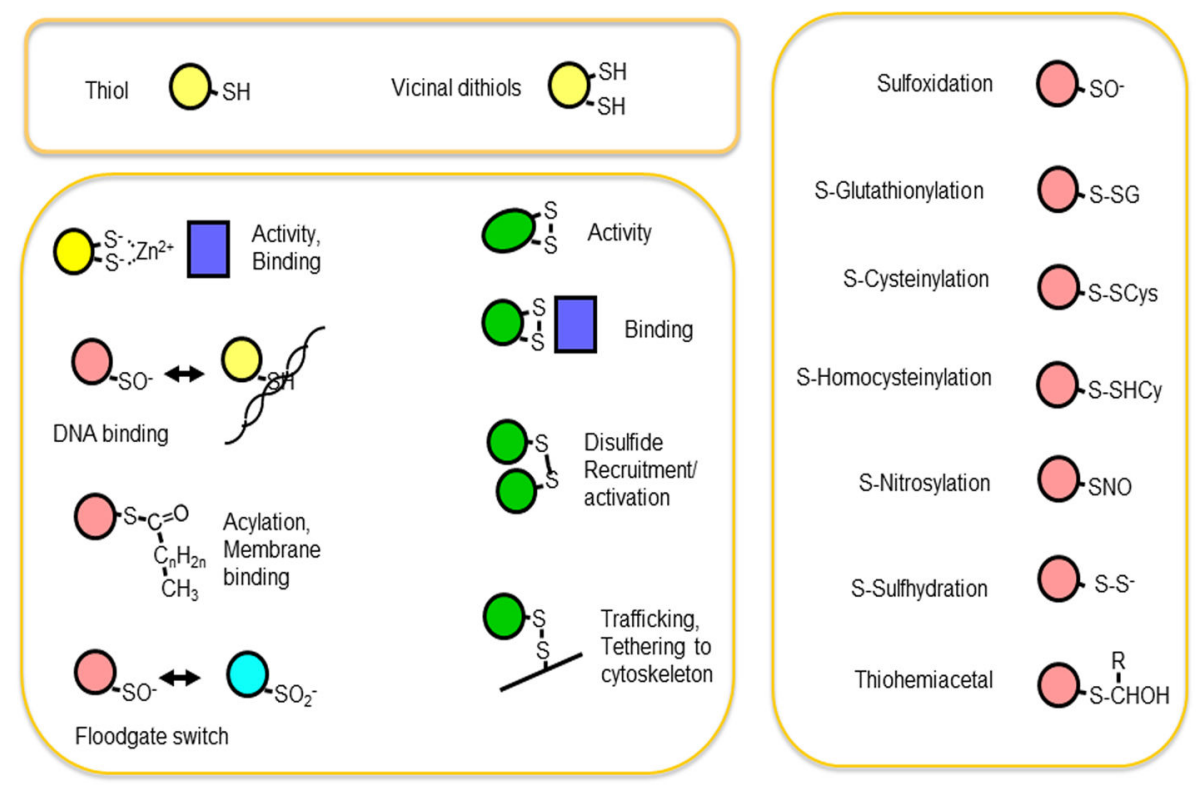

\section{Figure 3.}

The Cys proteome exists in a multidimensional functional space. While many Cys are contained within internal protein structures and not accessible to reversible modifications or interactions, Cys is a polar amino acid commonly found on the surface of proteins. In the vicinity of cationic amino acids, Cys can undergo ionization to a thiolate, which readily binds transition metals and is reactive with oxidants and electrophiles. These characteristics are associated with a large number of covalent modifications and ionic interactions, which are used in control of protein activity, structure, subcellular distribution, cell signaling, macromolecular interactions and trafficking. As shown on the top left, thiols are present in proteins as monothiols and vicinal dithiols; in some proteins larger clusters are also present. Modifications of monothiols are presented on the right, and functional responses to modification of monothiols and vicinal dithiols are shown on the lower left. 


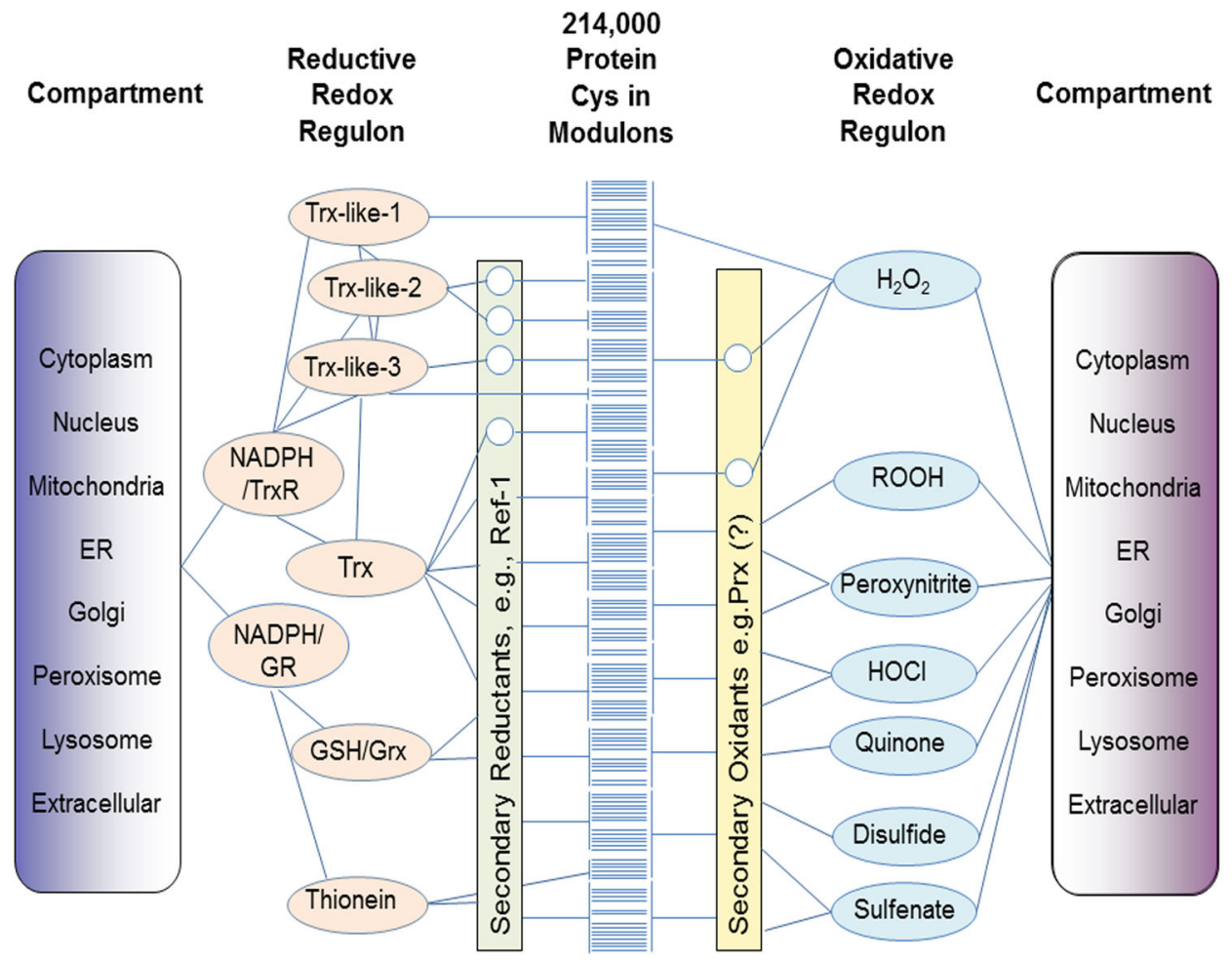

Figure 4.

Hierarchical redox structure for control of the redox proteome. Protein Cys residues are maintained in kinetically controlled redox states dependent upon opposing reductive and oxidative systems. An overriding level of control occurs at the physical level of subcellular compartmentation because of restricted redox communication between compartments. Within compartments, reductive systems are conceptualized as occurring in redox regulons, in which primary reductant systems such as NADPH/thioredoxin reductase or thioredoxin function as hubs controlling multiple redox nodes. Oxidative processes are depicted as occurring through opposing redox regulons, such as a $\mathrm{H}_{2} \mathrm{O}_{2}$ redox regulon. Many Cys are directly controlled by secondary reductant or oxidant systems, and these are presented as additional levels of organization within the hierarchical structure. Individual Cys residues are conceptualized as occurring in redox modules in which Cys in different proteins have evolved to share common redox properties, providing coordination of functional systems. Based upon known reaction types and specific examples, one can extrapolate that such a structure is sufficient to provide specific control of all 214,000 Cys encoded in mammalian genomes. 


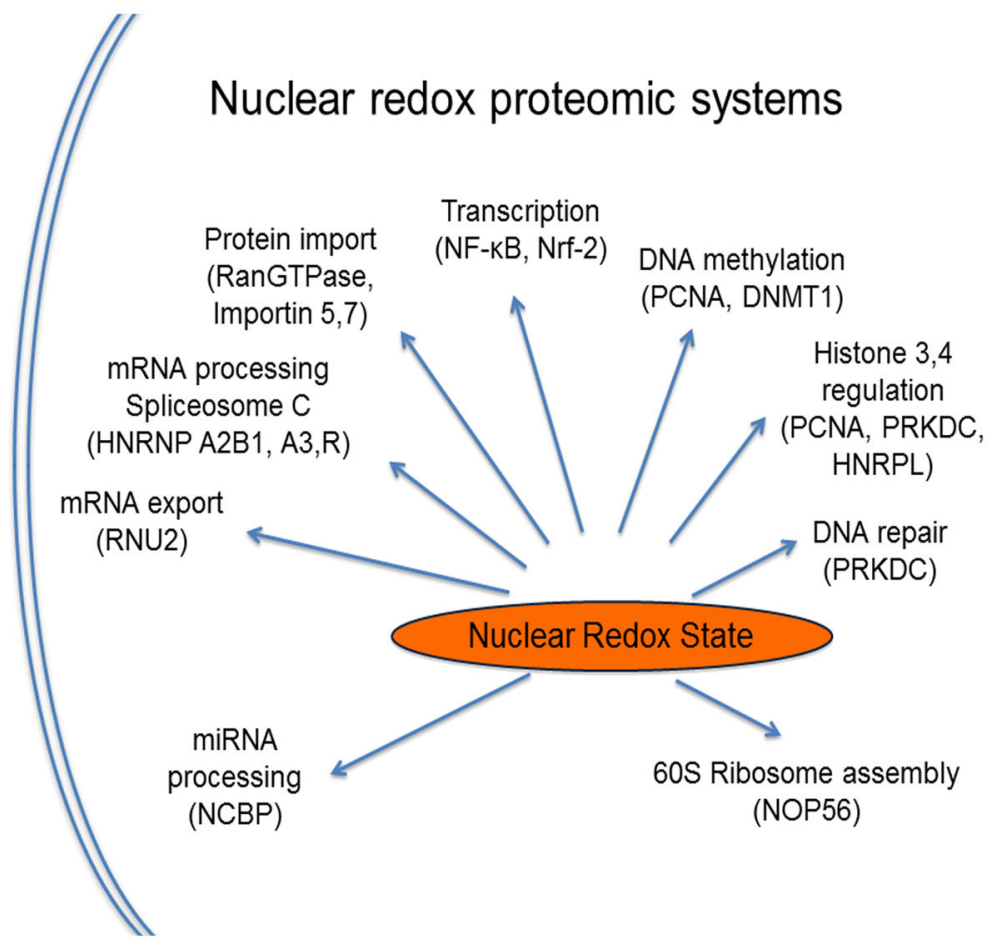

\section{Figure 5.}

Functional systems and representative proteins with redox-sensitive thiols in cell nuclei.

Multiple Cys residues are redox-sensitive in some proteins. Mass spectrometry-based redox proteomic analysis enables the measurement of redox state of multiple proteins in different subcellular compartments in response to diverse extracellular signals. This figure is derived from data reported in (Go et al., 2011) and illustrates redox-sensitive nuclear proteins that appear to be organized into redox modules. In such modules, multiple protein Cys have similar redox dependences with a character suggesting that redox mechanisms coordinate function. Redox-sensitive nuclear proteins are; DNMT1, DNA methyltransferase; HNRNP, heterogeneous nuclear ribonucleoproteins; NCBP, Nuclear cap-binding protein; NOP56, Nucleolar protein 56; PCNA, Proliferating cell nuclear antigen; PRKDC, DNA-dependent protein kinase catalytic subunit; RNU2, U2 small nuclear ribonucleoprotein. 


\section{Table 1}

Key Components for Modeling of Thiol Redox Circuits

\begin{tabular}{|c|l|}
\hline Compartmentation & $\begin{array}{l}\text { Cytoplasm, mitochondria, endoplasmic reticulum, peroxisomes, lysosomes, nuclei, extracellular } \\
\text { compartments }\end{array}$ \\
\hline \multirow{3}{*}{ Redox regulon } & Specific reductant system; NADPH, Trx, GSH, etc \\
\cline { 2 - 3 } Hierarchical network structure & Specific oxidant system; $\mathrm{H}_{2} \mathrm{O}_{2}, \mathrm{ROOH}$, quinone, disulfide \\
\hline \multirow{5}{*}{} & Secondary reductant and oxidant systems \\
\cline { 2 - 3 } & Modulon composition \\
\cline { 2 - 3 } & Dynamic re-scaling of reaction rates (abundance, $\mathrm{pH}, \mathrm{Zn}^{2+}$, etc \\
\cline { 2 - 2 } & Dynamic redistribution (microcompartmentation) \\
\hline
\end{tabular}

